Discussion

Papers

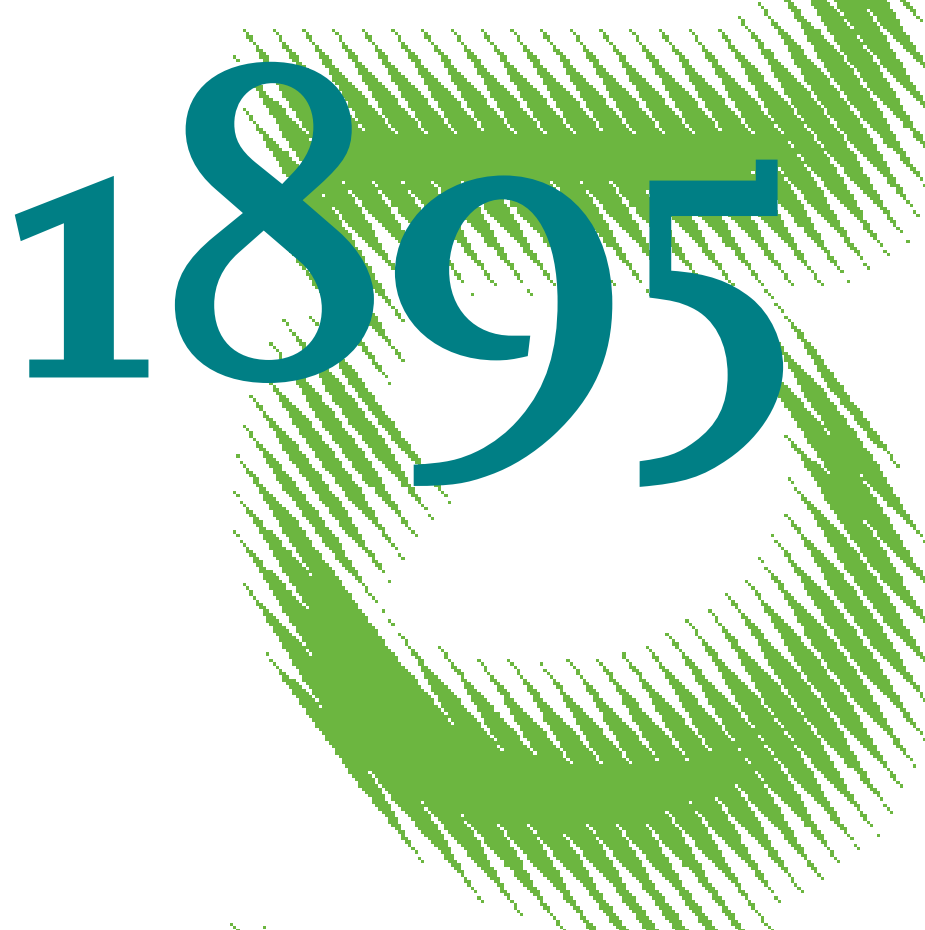

The Effectiveness of FX Interventions: A Meta-Analysis 
Opinions expressed in this paper are those of the author(s) and do not necessarily reflect views of the institute.

IMPRESSUM

(C) DIW Berlin, 2020

DIW Berlin

German Institute for Economic Research

Mohrenstr. 58

10117 Berlin

Tel. +49 (30) $89789-0$

Fax +49 (30) $89789-200$

http://www.diw.de

ISSN electronic edition 1619-4535

Papers can be downloaded free of charge from the DIW Berlin website:

http://www.diw.de/discussionpapers

Discussion Papers of DIW Berlin are indexed in RePEc and SSRN:

http://ideas.repec.org/s/diw/diwwpp.html

http://www.ssrn.com/link/DIW-Berlin-German-Inst-Econ-Res.html 


\title{
The Effectiveness of FX Interventions: A Meta-Analysis*
}

\author{
Lucía Arango-Lozano ${ }^{\dagger}$ \\ Daniela Rodríguez-Novoa ${ }^{\S}$
}

\author{
Lukas Menkhoff ${ }^{\ddagger}$ \\ Mauricio Villamizar-Villegas
}

\begin{abstract}
There is ample empirical literature centering on the effectiveness of foreign exchange intervention (FXI). Given the mix of objectives and country-heterogeneity, the general lack of consensus thus far is no surprise. We shed light on this debate by conducting the first comprehensive meta-analysis in the FXI literature, with 279 reported effects that stem from 74 distinct empirical studies. We cover estimations conducted in 19 countries across five decades. Overall, our meta-survey reports an average depreciation of domestic currency of $1 \%$ and a reduction of exchange rate volatility of $0.6 \%$, in response to a $\$ 1$ billion US dollar purchase. Results are qualitatively confirmed but smaller in size under fixed and random-effect estimations. When narrowing in on different economic factors, we find that effects are magnified for cases consistent with the monetary trilemma (greater if financial openness and monetary independence are low). Effects are also larger in emerging than advanced economies, when banking crises remain mild, and when interventions are large in size and are announced.
\end{abstract}

JEL Classification: C83, E58, F31

Keywords: foreign exchange intervention, exchange rate, meta-analysis

${ }^{*}$ We especially thank Charles Engel (University of Wisconsin) for useful comments and suggestions. We also thank Camilo Miranda and Alejandra Ruiz for their valuable research assistance. Comments received at the International Finance and Banking Society Conference, IFABS-2019, and at seminars at the Central Bank of Colombia are highly appreciated. The opinions contained herein are the sole responsibility of the authors and do not commit Banco de la República nor its Board of Directors.

${ }^{\dagger}$ Central Bank of Colombia; email: laranglo@banrep.gov.co

${ }^{\ddagger}$ Humboldt University Berlin, German Institute of Economic Research; email: lmenkhoff@diw.de

${ }^{\S}$ Central Bank of Colombia; email: drodrino@banrep.gov.co

ฯ Central Bank of Colombia; email: mvillavi@banrep.gov.co 


\section{Introduction}

There is ample empirical literature centering on the effectiveness of foreign exchange intervention (FXI). In fact, some studies postulate whether central banks should target the exchange rate (be it the level or volatility) alongside other more standard objectives, such as safeguarding inflation and supporting output. This is particularly relevant for FXI practitioners, which, according to Ghosh et al. (2018), are mostly countries that experience rapid domestic credit growth coupled with surges in capital inflows.

In theory, FXI effectiveness is bounded by the monetary trilemma, i.e. the impossibility of simultaneously allowing for free capital flows, having an autonomous monetary policy, and a managed exchange rate. Put differently, policymakers can only gain control of the exchange rate if they abandon monetary policy or enact capital controls. Given the mix of objectives and country-heterogeneity, it comes as no surprise that there is a general lack of consensus regarding the effects of FXI in the existing literature.

We shed light on this debate, by bringing together the literature that empirically documents exchange rate effects. Hence, our study is the first and only comprehensive meta-analysis conducted in the FXI literature, with 279 reported effects (158 on the exchange rate level and 121 on exchange rate volatility) stemming from 74 distinct empirical studies. It covers estimations conducted in 19 countries and across five decades: the 1970s, 1980s, 1990s, 2000s, and 2010s; practically the entire history since the demise of the Bretton Woods System in the early 1970s.

When compiling this wealth of studies, our outcomes of interest are measured in the same informative unit (while most of the meta-analysis literature standardizes effects into a common scale-free metric). Namely, exchange rate changes and volatility are denoted in percentages, and all of the effects are scaled in response to a $\$ 1$ billion US dollar intervention. Thus, we gain a direct interpretation of the results by performing a meta-analysis using economic effect sizes as opposed to statistical effect sizes (see Stanley and Doucouliagos, 2012). Beyond this main analysis, we also examine whether the magnitude and significance of the effects vary depending on three types of country-year economic factors: variables related to the monetary trilemma indices (i.e. degree of monetary autonomy and financial openness), variables related to the way interventions are conducted (e.g., secrecy, intervention type, intervention size), and variables related to the macroeconomy (e.g., the level of financial deepening, number of financial crises, or the income group). 
Our survey reports an average depreciation of domestic currency of $1 \%$ in response to a $\$ 1$ billion net dollar purchase. We obtain similar effects when separately considering purchases and sales of US dollars, namely a $0.9 \%$ depreciation and 1.0\% appreciation, respectively. However, we believe that the measures of fixed effects (FE) and, in particular, random effects (RE) are more accurate, since they assume that studies share a common true effect size, but are allowed to differ in sampling error (for the case of FE) and also in between-study heterogeneity (for the case of RE). Under RE without covariates, we find a depreciation of $0.04 \%$ in response to a $\$ 1$ billion net dollar purchase.

Notwithstanding, when narrowing in on different economic factors, we find significant (and larger) RE estimates for cases consistent with the monetary trilemma. For instance, we find greater effects when financial openness is low ( $0.24 \%$ versus $0.04 \%$ when high), when financial openness in tandem with monetary independence is low $(0.16 \%$ versus $0.03 \%$ when high), and in cases when departures from the covered interest rate parity (CIP) are above the mean $(0.15 \%$ versus $0.04 \%$ when below). Additionally, and in line with the result on financial openness, restrictions on capital flows show an increase in intervention effectiveness. In particular, we find a depreciation of $0.16 \%$ when restrictions on outflows are above the mean compared to $0.04 \%$ when below the mean.

Additionally, the effects are magnified when interventions are of relatively large size $(0.04 \%)$, announced $(0.30 \%)$, when using derivatives in the forward market $(0.13 \%)$, and when the country explicitly targets exchange rate volatility $(0.32 \%)$, as opposed to a given level. Finally, macroeconomic variables that have a magnifying effect on FXI include: income group (for high and upper-middle income countries), financial crisis (when undergoing less banking and currency crises), financial deepening (when low), dollar-denominated sovereign debt (when high), and credit rating (when high).

The literature that documents effects on exchange rate volatility is narrower and we note that there is less agreement on a standard volatility measure $1^{1}$ Bearing this in mind and using a sample of 121 observations, we find a reduction of FX volatility of $0.6 \%$ in response to a $\$ 1$ billion net dollar purchase. However, Fixed- and Random-effects are almost negligible. And, while we also find that results are consistent with the trilemma indices, the overall magnitude of the effects remains small.

\footnotetext{
${ }^{1}$ In some cases, researchers estimate exchange rate volatility using Autoregressive Conditional Heteroskedasticity models. Other studies use market-based measures, such as the square of exchange rate changes.
} 
All of our results are corroborated by meta-regressions and by adjusting for synthetic effect sizes per study i.e., where we give each study - not each result- the same weight. Finally, while we find evidence of a moderate publication bias, we show that bias-corrected coefficients yield almost identical results.

In the related literature, we recognize useful surveys on the effects of FXI after the benchmark study by Sarno and Taylor (2001). Such is the case of Neely (2005), Menkhoff (2013), Villamizar-Villegas and Perez-Reyna (2017), Chamon et al. (2019a), and Chamon et al. (2019b), who provide a descriptive report of 41, 25, 34, 29, and 11 findings, respectively. ${ }^{2}$ Also, there is one earlier, but narrow meta-analysis about FXI: The study by Brychka et al. (2019) covers 12 papers (35 total effects) due to its restrictive selection criteria. Our investigation, however, yields new and strikingly different results for three main reasons: (i) we include covariates in our meta-analysis, which not only allows us to explain part of the heterogeneity in the effects, but also to characterize FXI effectiveness as a function of country-year level variables, (ii) our study represents not a very selective but a comprehensive sample, and (iii) despite an overlap of 11 studies, only 3 of them exactly match our data. $3^{3}$

A completely different approach provide Fratzscher et al. (2019) in their study of sterilized foreign exchange interventions, relying on data of 33 central banks over up to 15 years. This analysis of private daily data is broader, but shorter, than our meta-study. Also different from our data, they consistently apply the same methodological approach to all of the analyses, i.e. an event study complemented by a matching approach, while we rely on the various methods used by the primary studies. Interestingly, they also find effectiveness of FXI and share some of our further findings on conditions of successful FXI as we discuss in the conclusions.

A final approach is applied by macro-economically oriented studies that rely on monthly or quarterly changes in FX reserves as a proxy for FXI, such as Blanchard et al. (2015) or Adler et al. (2019). While this approach can hardly be compared to our analysis, mainly based on daily data, the mentioned papers also find that FXI can have an impact on the course of exchange rates.

Our paper proceeds as follows. In Section 2, we describe our data and web-scrapping search. In Section 3, we present the standard meta-analysis techniques. In Section 4, we

\footnotetext{
${ }^{2}$ Pioneer surveys include Dornbusch (1980), Dominguez and Frankel (1993), and Edison (1993).

${ }^{3} \mathrm{In}$ Appendix F, we report the findings that do not match, including some studies that slightly modified their findings in later versions.
} 
report our findings for both the level and volatility of the exchange rate. In Section 5, we explore whether there is evidence of a publication bias and present robustness checks. Finally, Section 6 concludes by providing some policy recommendations.

\section{Data and Web-search}

\subsection{Web-Search}

The initial web-scrapping search included different sources such as Repec, Scopus, Mendeley, central banks, and NBER. We searched for studies containing "Foreign + Exchange + Intervention" (in any order, joint or separate) either in the title or abstract, and found a total of 535 unique (non-duplicated) studies $4^{4}$ Next, we eliminated those that fell under any of the following criteria: (i) those written in any language other than English, (ii) those evaluating exchange rates not related to the US dollar, (iii) those using either extremely high (intra-day) or low (yearly) frequency, and (iv) those without an empirical evaluation of foreign exchange intervention. Of the 74 resulting studies, we gathered 279 separate findings.

For comparability purposes, the impulse and response of each finding were re-scaled. In terms of the response, we define the exchange rate as the value of local currency in units of foreign currency (US dollar), in \% changes, i.e. positive values indicate a depreciation of domestic currency. In terms of the impulse, we scaled results to a $\$ 1$ billion net US dollar purchase (i.e. sales of foreign currency take on negative values). While our benchmark exercises evaluate the effects of net purchases, in Appendix B we consider purchases and sales separately, when the study explicitly allows for this distinction.

We faced several challenges. Among them was the extraction of results when a particular study covered multiple periods of analysis. We proceeded by recording each period as a separate observation, and in some tests we assigned a relative weight to that observation as the inverse of findings per study, i.e. if a study reports 5 findings, each finding weighs $20 \%$. On average, we record 3 findings per study, with a standard deviation of 4 findings. Another challenge dealt with insufficient information in order to scale effects to an impulse of a $\$ 1$ billion dollar intervention. This was especially the case for studies that used dummy variables rather than intervention amounts. We proceeded by gathering official intervention data from each country's central bank, regarding the average amount of dollars traded during

\footnotetext{
${ }^{4}$ Our last web search was conducted in January 2019. We initially collected 1,308 studies, but only kept the most updated or published version.
} 
the specified periods. In cases where official FXI data was absent, we obtained information either from the Federal Reserve Economic Data (FRED) or the CEIC. As last resource, we emailed the corresponding authors.

In some cases, the standard errors of estimates were not reported. When t-statistics were documented, we simply divided the effect size by the reported statistic. When only the p-value was reported, we followed the procedure in Vooren et al. (2019) to convert p-values as follows: p-values below and up to 0.01 were assigned t-statistics of 2.58 , p-values between 0.01 and 0.05 were assigned t-statistics of 1.96 , p-values between 0.05 and 0.10 were assigned t-statistics of 1.65 , and p-values above 0.10 were assigned t-statistics of 0.99 . Among the literature we found studies that reported standard errors with zero value, possibly due to rounding or limited decimals in their reports (Aguilar and Nydahl, 2000, Kriljenko et al., 2006, Hoshikawa, 2008, Trivedi and Apte, 2016, Katusiime and Agbola, 2018). For these we used a 2.58 t-statistic threshold instead. Additionally, some studies claimed statistical significance when t-statistics were lower than 1.65 (Utsunomiya, 2013, Broto, 2013, Castrén, 2004). While we understand that each study can establish its own significance level, we nonetheless proceeded with the more standard "rule of thumb" threshold of statistical significance levels of up to $10 \%$.

One potential concern relates to the overall concept of effectiveness. Namely, a central bank can intervene in the FX market for a variety of reasons, including the build-up of international reserves. In that particular case, effectiveness is not tied-in to any particular exchange rate movement. Fortunately, the vast majority of studies covered in our investigation explicitly state an objective tied in to some statistical moment of the exchange rate (e.g. to curb volatility or influence the level of the exchange rate). We proceeded by recording the central bank's intended objective, as documented by the study. Further, we compare this to our own market-based indicator, namely the amount of dollar sales over the total intervention amount. We believe that cases with large asymmetries (when taking on extreme values close to unity or zero) most likely targeted the exchange rate level, since FX volatility operations generally entail an even number of purchases and sales, provided that the underlying distribution of exchange rate changes is also symmetric.

A final concern is that accompanying interest rate changes (especially those induced by the selling and purchasing of foreign currency) can over- or underplay exchange rate effects. We nonetheless sidestep this problem by reviewing sterilized operations, i.e. those designed to leave the domestic money supply (and thus domestic interest rates) unchanged. 


\subsection{Data Source}

We gathered country-year specific information in order to characterize FXI effectiveness as a function of: (i) trilemma indices, (ii) the way interventions were conducted, and (iii) macroeconomic variables. Some of these data were obtained directly from each study, e.g. employed methodology, FX mechanism, whether interventions were measured as continuous or binary, size of interventions, intended objective, and whether interventions were announced. The last three in particular were corroborated with each country's central bank website when the information was available. Further, we recorded asymmetries in US dollar purchases versus dollar sales, i.e. amount of sales over total intervention. We believe that this marketbased indicator can suggest some degree of fear of appreciation/depreciation, when taking on extreme values (close to zero or unity).

Other variables and their data source include:

- Coarse exchange rate regimes: Five regime categories that matched our country-year sample were used: currency board, pre-announced crawling peg, pre-announced crawling band, freely floating, and freely falling (source: Ilzetzki et al., 2019).

- Trilemma measures: Indices of Financial Openness and Monetary Autonomy were used (source: Aizenman et al., 2008). Additionally, annual departures from the CIP were computed for each country, as $\ln \left(F_{t+1} / S_{t}\right)-\left(i_{t}-i_{t}^{*}\right)$, where $F$ is the forward exchange rate to be exercised in period $t+1, S$ is the spot exchange rate, and $i-i^{*}$ denotes the interest rate differential (from yearly treasury bonds) between the home and foreign country; the foreign country being always the United States (source: Bloomberg).

- Capital Controls: Three indices were used: Overall Restrictions Index, Overall Inflow Restrictions Index, and Overall Outflow Restrictions Index (source: Fernández et al., 2016).

- Financial Crisis: Two indicators that matched our country-year sample were used: Systemic Banking Crisis and Currency Crisis (source: Laeven and Valencia, 2020). More specifically, we computed the fraction of crisis years (as a share of total years) in each finding. For the banking crises, we also used an additional measure of intensity, by using the county's output loss in the year of the crisis.

- Financial Deepening: Measured as domestic credit to the private sector, as a share of GDP (source: World Development Indicators).

- GDP classification: Four income groups were used: Low, Lower-Middle, Upper-Middle, and High income (source: IMF FMEconGroup). 
- Publication Type: Information concerning the study's publication type (working paper or published article), impact factor, and number of citations were recorded as reported in Google Scholar as of December 31, 2019.

- Credit Ratings: Sovereign Grade Ratings of 5-year maturities bonds (source: Standard and Poor's (S\&P) Services, Moody's Investors Service and Fitch Ratings). For Fitch and S\&P, we assigned the lowest grade (DDD) a value of 1 and up to 25 (AAA). For Moody's, we assigned the lowest grade $(\mathrm{C})$ a value of 1 and up to 21 (Aaa).

- Other Macroeconomic variables were used, including: FX Volatility, International Reserves, and Sovereign debt (source: Bloomberg).

\subsection{Descriptive Characteristics}

This section provides descriptive statistics for the 279 reported results stemming from 74 distinct studies $5^{5}$ Figure 1 shows the 19 surveyed countries, sub-categorized by announced versus secret (dirty) interventions. As shown, some countries enacted various types of mechanisms. For example, in Colombia the central bank intervened secretly during 2004-2007, but also carried out pre-announced auctions during 2008-2014. We note that, as a result of our selection criteria, concerted initiatives are not considered (e.g. Smithsonian Agreement 1971, Plaza Accord 1985, Louvre Accord 1987, Chiang Mai Initiative 2000, and Pittsburgh Agreement 2009); this may lead to an underestimation of our results as concerted FXI can be more powerful than isolated ones (e.g. Frankel, 2016). Also, interventions with currency trades different from the US dollar are omitted. Relatedly, the United States is left uncolored because it represents our benchmark case (all studies refer to purchases or sales of US dollars versus the domestic currency). These reasons, coupled with the fact that official information on FXI is scarce, limit the extent of surveyed countries.

Further, Table 1 breaks down the number of studies in our analysis by country and by decade. While information is obtained from 74 distinct studies, some cover more than one country and/or decade. Japan is the country with the most observations (52), followed by Colombia (21). As observed, most studies center their analysis during the 1990's and 2000's, which coincides with many emerging market economies adopting a flexible exchange rate regime. It also coincides with major exchange rate and financial crises: the European Monetary System crisis (1992), the East Asia crisis (1997-1999), and the financial world crisis

\footnotetext{
${ }^{5}$ In the supplementary appendix we provide a detailed description of each study, including the country, time period, currency, data frequency, methodology and main findings.
} 
(2008-2009).

Interestingly, Figure 2 shows a positive linear time trend for all effect sizes, when sorted by either year of publication or initial year of the study's data sample 6 This trend is maintained even after excluding the two most extreme outliers. At face value, this could indicate a gain in exchange rate influence by central banks through time. However, we recognize that this time trend can be due to a variety of reasons, including new methodologies, different contexts, or mechanisms. We shed some light on the influence of some of these factors in Section 4.

In theory, FXI effectiveness is bounded by the monetary trilemma, i.e. the impossibility of simultaneously allowing for free capital flows, having an autonomous monetary policy, and a managed exchange rate. Figure 3 plots our surveyed studies grouped by country and by decade, and categorized by Aizenman et al. (2008)'s trilemma indices of Financial Openness (y-axis) and Monetary Autonomy (x-axis). As observed, the top right quadrant is more prone to the trilemma and thus we would expect FXI to be less effective. Consistently, in that quadrant only $26 \%$ of studies report significant results, as opposed to $38-50 \%$ for the other quadrants. Similarly, in Figure A1 of Appendix A we plot individual studies for the cases of Japan, Colombia, Turkey, Australia, India, and Mexico.

Finally, we recognize that a key issue for policymakers, besides the magnitude and significance of exchange rate effects, is the duration of effects. Unfortunately, most studies in the FXI literature shy away from this issue, and report only contemporaneous effects.7 In total, we observe only 18 observations (from 10 studies) that document impulse-response type of results for the exchange rate level and volatility, across different time horizons. Table 2 summarizes the few existing findings and shows an average duration of 21 and 56 working days (roughly 1 and 3 months), when targeting the exchange rate level and volatility, respectively.

\footnotetext{
${ }^{6}$ The slope coefficient of a linear regression (i.e. regressing effect sizes on a categorical year variable) is 0.136 percentage points (with a standard error of 0.061 ) for the year of publication and 0.143 percentage points (with a standard error of 0.058) for the initial year of the study's data sample, both statistically significant at the $5 \%$ significance level. This implies that every year the effect sizes gain an average of 0.14 percentage points.

${ }^{7}$ An exception is Menkhoff et al. (2020), who report significant effects over weeks and months for four major central banks, however, this study appeared after we had closed collecting data.
} 
Figure 1: Countries with Announced vs Secret Interventions

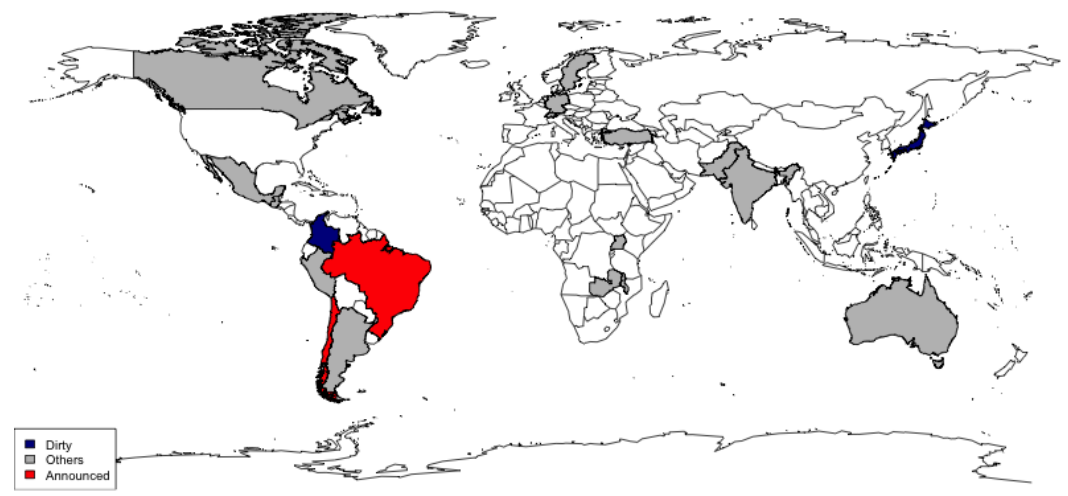

The Figure shows the 19 surveyed countries, sub-categorized by announced versus secret (dirty) interventions. The United States is not colored because it represents our benchmark case: all studies refer to purchases or sales of US dollars versus the domestic currency.

Table 1: Surveyed Countries and Decades

\begin{tabular}{lcccccc}
\hline \hline Country & 1970 & 1980 & 1990 & 2000 & 2010 & Total \\
\hline ARGENTINA & 0 & 0 & 0 & 1 & 0 & 1 \\
AUSTRALIA & 0 & 5 & 3 & 2 & 0 & 10 \\
BRAZIL & 0 & 0 & 1 & 5 & 4 & 10 \\
CANADA & 0 & 1 & 1 & 0 & 0 & 2 \\
CHILE & 0 & 0 & 1 & 3 & 2 & 6 \\
COLOMBIA & 0 & 0 & 3 & 10 & 8 & 21 \\
GERMANY & 1 & 4 & 3 & 0 & 0 & 8 \\
GUATEMALA & 0 & 0 & 0 & 1 & 1 & 2 \\
INDIA & 0 & 0 & 4 & 1 & 3 & 8 \\
JAPAN & 0 & 1 & 26 & 21 & 4 & 52 \\
MALAWI & 0 & 0 & 0 & 1 & 0 & 1 \\
MEXICO & 0 & 0 & 4 & 4 & 2 & 10 \\
PAKISTAN & 0 & 0 & 0 & 1 & 0 & 1 \\
PERU & 0 & 0 & 0 & 2 & 1 & 3 \\
SWEDEN & 0 & 0 & 1 & 0 & 0 & 1 \\
SWITZERLAND & 0 & 1 & 1 & 0 & 0 & 2 \\
TURKEY & 0 & 0 & 0 & 8 & 2 & 10 \\
UGANDA & 0 & 0 & 0 & 1 & 1 & 2 \\
ZAMBIA & 0 & 0 & 2 & 1 & 1 & 4 \\
Total & 1 & 12 & 50 & 62 & 29 & 154 \\
\hline \hline
\end{tabular}

Authors' calculations. Each value denotes the number of studies in our sample by country and by decade in which the empirical exercise took place. While there is a total of 74 distinct studies in the survey, note that some studies cover more than one country and/or decade. 
Fiøure 2: Effects Sizes through Time

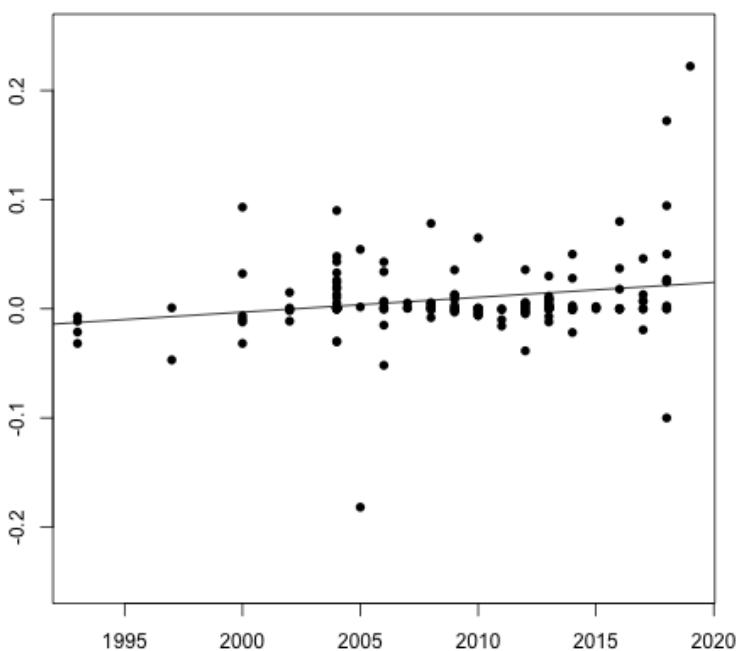

(a) Year of publication

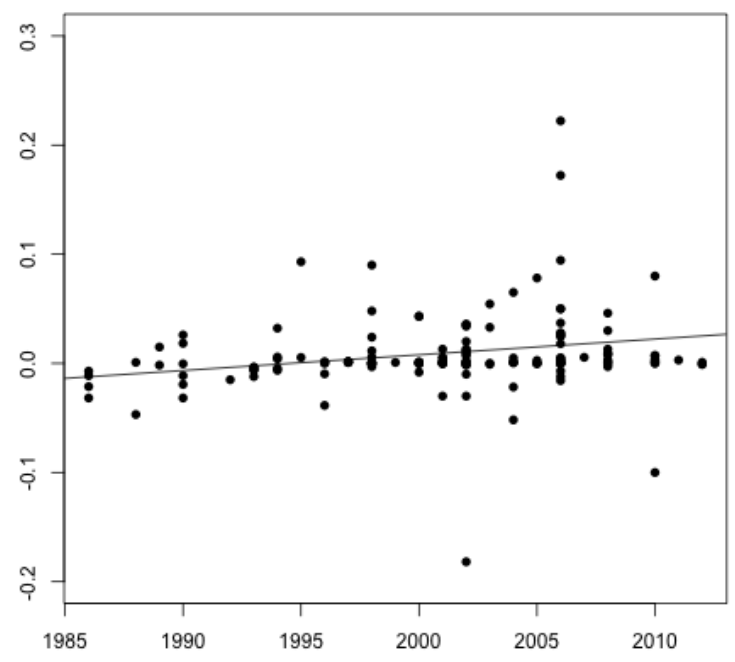

(b) Year of Study

The Figure shows a positive linear time trend for effect sizes, measured as exchange rate changes (percentage points, y-axis) in response to a $\$ 1$ billion net US dollar purchase. Panel (a) shows the year (x-axis) of publication and panel (b) shows the year in which the empirical exercise took place. The slope coefficient of linearly regressing effect sizes on a categorical year variable is 0.136 (with a standard error of 0.061 ) for panel (a) and 0.143 (with a standard error of 0.058) for panel (b), both statistically significant at the $5 \%$ significance level.

Figure 3: Trilemma Indices

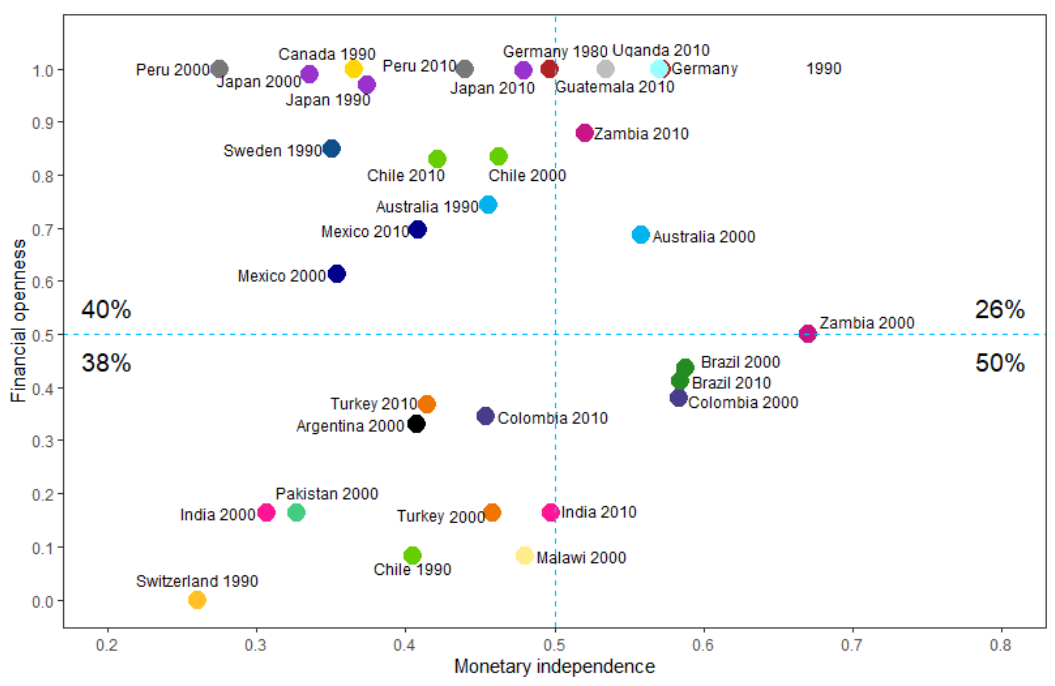

The Figure plots our surveyed studies grouped by country and by decade, and categorized by the trilemma indices proposed in Aizenman et al. (2008), namely the degree of financial openness (y-axis) and monetary autonomy (x-axis). In theory, the top right quadrant is more prone to the monetary trilemma. The values (in \%) denote the fraction of studies with significant results in the expected direction: depreciation (appreciation) of domestic currency after purchases (sales) of foreign currency. 
Table 2: Duration of FXI Effects

\begin{tabular}{lccc}
\hline \hline & Observations & Mean & SD \\
\hline Duration in days (FX Level) & 13 & 21.5 & 31.7 \\
Duration in days (FX Volatility) & 5 & 56.0 & 102.9 \\
\hline \hline
\end{tabular}

Authors' calculations. The Table shows the average duration of FXI effects, on both the level and volatility of the exchange rate. Values denote the number of working days. In total, we observe 18 observations from 10 distinct studies that document impulse-response type of results for either the exchange rate level or volatility. Studies providing this information are: Egert and Lang (2005); Brause (2008); Echavarría et al. (2010); Echavarría et al. (2014); Keefe and Rengifo (2015); Tobal and Renato(2016); Kitamura (2017); Onder and Villamizar-Villegas (2018); Kuersteiner et al. (2018); and Vargas-Herrera and Villamizar-Villegas (2019)).

\section{Methodology}

Meta-analysis is a useful quantitative method that synthesizes the combined effect of multiple studies that center on the same empirical question, in our case foreign exchange interventions. The main objective of this method is to determine whether outcome variables are statistically different from zero and to explain the potential within and between-study heterogeneity, all within a fully replicable framework.

To perform meta-analysis, many studies standardize individual effects into a common scale-free metric, since outcomes and treatments are either different or measured differently across studies. In those cases, the effect size is generally defined as the mean difference in outcomes between treatment and control groups, as a share of the pooled standard deviation of the dependent variable. Fortunately, an attribute of our investigation is that our variables of interest are measured across studies in the same informative unit. Namely, exchange rate changes and volatility are denoted in percentages, and all of the effects are scaled in response to a $\$ 1$ billion net US dollar intervention. Thus, we gain a direct interpretation of the results, by using economic effect sizes as opposed to statistical effect sizes.

We first estimate the overall effect of FXI under two distributional assumptions, namely fixed (FE) and random effects (RE). Specifically, the former assumes that observed effects are distributed around a common "true" effect size, and therefore the only source of variance is due to measurement error within each study. In contrast, the latter allows for both withinstudy and between-study measurement error. We think that both kinds of measurement error are relevant in our case as studies cover quite heterogeneous cases. Therefore, the RE-estimations seem to be preferable.

Next, we estimate a full pooling least squares meta-regression, where each effect size is weighted by its inverse variance. Note that the variance differs on whether we assume fixed 
or random-effects. This multivariate approach allows us to control for macroeconomic or other characteristics and is exemplified as follows:

$$
E S_{i}=\beta+\alpha S E_{i}^{2}+\sum_{j} \gamma_{j} X_{j i}+\nu_{i}
$$

where $E S_{i}$ denotes the study-level effect size, $S E_{i}$ is the reported standard error, and $X_{j i}$ corresponds to the vector of country-year covariates that relate to both the way interventions were conducted and trilemma indices. We estimate equation 1 using multiple effect sizes per study and account for heteroscedasticity by clustering standard errors at the study level. For robustness, we also aggregate all effects per study into one synthetic effect size.

Finally, we examine whether there is evidence of publication selection bias, which exists when editors, referees, or researchers are inclined towards statistically significant results, often overstating the magnitude of the results. We proceed by first performing a visual inspection test based on plotting the effect sizes against precision (inverse of standard errors) in a funnel-plot. Intuitively, results with low power (high variance) should scatter at the bottom, while high precision effects should bunch together around the mean, graphically creating an inverse funnel. According to Stanley and Doucouliagos (2011), asymmetry in the funnel would be a sign of publication bias.

To complement this visual test, we estimate a "precision-effect test" known as the Funnel Plot Asymmetry Test (FAT-PET), based on the following Weighted Leas Squares (WLS) meta-regression:

$$
E S_{i}=\alpha_{0}+\beta_{0} S E_{i}+\nu_{i}
$$

where the weights correspond to $1 / S E_{i}^{2}$. A rejection of the null $\left(\beta_{0}=0\right)$ indicates publication bias. Meanwhile, $\alpha_{0}$ corresponds to the genuine empirical effect. For robustness, we perform a Precision Effect Estimate with Standard Error test (PEESE), in order to asses for possible bias in the FAT-PET test results (Stanley, 2001). This entails estimating the following WLS regression:

$$
E S_{i}=\beta_{0}+\alpha_{0} S E_{i}^{2}+\nu_{i}
$$

where weights also correspond to $1 / S E_{i}^{2}$ and $\beta_{0}$ indicates the magnitude of the empirical 
effect corrected for publication bias.

\section{Results}

Our main results are presented in this section. We conduct standard meta-analysis techniques, following the works of Stanley and Jarrell (1989), Lipsey and Wilson (2001), Stanley (2001), Knapp and Hartung (2003), and Stanley and Doucouliagos (2012). In essence, we present estimates for forest-plots and full-pooling meta-regressions, explaining FXI effectiveness regarding the exchange rate level (Section 4.1) and exchange rate volatility (Section 4.2).

\subsection{FX Level}

Tables 3 and 4 report our benchmark Meta-analysis estimates. In total, they show an average depreciation of domestic currency of $1 \%$ in response to a $\$ 1$ billion net US dollar purchase. However, we believe that the measures of fixed effects (FE) and random effects (RE) are more accurate, since they assume that studies share a common true effect size, but are allowed to differ in sampling error (for the case of FE) and in between-study heterogeneity (for the case of RE). Under RE without covariates, we find a depreciation of $0.04 \%$ in response to a $\$ 1$ billion net dollar purchase. The preferred RE estimate is below the simple mean which is a common result in meta-studies. The lower effect mainly comes from the weighting of studies by which sometimes extreme results of "small" studies (with little observations) are discounted. For ease in readability, in Figure 4 we depict various random effects for selected variables, sorted by magnitude.

When narrowing in on various economic factors as shown by the RE estimations, we find significant and larger effects, especially for cases consistent with the monetary trilemma. Specifically, in the top panel of Table 3 we find greater effects when financial openness is low $(0.24 \%$ versus $0.04 \%$ when high), when financial openness in tandem with monetary independence is low $(0.16 \%$ versus $0.03 \%$ when high) and in cases when the CIP is violated ( $0.15 \%$ for when departures are above the mean versus $0.04 \%$ for when below the mean). Regarding exchange rate regimes, we find the largest effects for countries with a "preannounced crawling band" $(0.70 \%)$, followed by those with a "freely falling" rate $(0.29 \%) \mathrm{b}^{8}$ Also, in line with the above mentioned result on financial openness, restrictions on capital

\footnotetext{
${ }^{8}$ In Table E9 of Appendix E, we consider additional categories under the fine classification, as proposed in Ilzetzki et al. (2019). It shows that the sub-category with the highest effects corresponds to "pre-announced crawling band narrower than or equal to $\pm 2 \%$.
} 
flows show an increase in intervention effectiveness. In particular, we find a depreciation of $0.07 \%$ and $0.16 \%$ when restrictions on inflows and outflows are above the mean, respectively, compared to $0.06 \%$ and $0.04 \%$ when below the mean.

The bottom panel of Table 3 shows results relating to the mechanism under which interventions are conducted. For example, we find that auctions for the case of Colombia have the largest effects (5.2\%), which contrasts auctions carried out in Brazil, Mexico, and Turkey for which we find a null effect. Additionally, we find that random effects are magnified when using derivatives in the forward market (0.13\%), when interventions are announced $(0.30 \%)$, and when the central bank explicitly targets exchange rate volatility $(0.33 \%)$, as opposed to a given level $!^{9}$ Concerning the latter, we also use our own market-based indicator, namely the amount of USD sales over the total intervention amount. Essentially, we argue that cases with large asymmetries (when taking on extreme values close to unity or zero) most likely targeted the exchange rate level, since FX volatility operations generally entail a rather even number of purchases and sales. We find significant results for symmetric operations (quartiles 2 and 3) and also for those in quarter 4 (when a central bank conducts mostly sales). Finally, intervention size relative to total market turnover increases FXI effectiveness when it is above the median of our sample.

Table 4 reports the effects of FXI based on macroeconomic variables and information pertaining to each study. The top panel shows that effects are magnified according to: income group (for high and upper-middle income countries), financial crisis (when undergoing less banking and currency crises), financial deepening (when low), exchange rate volatility (when low), level of international reserves (when high), dollar-denominated sovereign debt (when high), and credit rating (when high). Regarding banking crises, results hold when adjusting for the intensity of each crisis, as explained in Laeven and Valencia (2020).

In the bottom panel we explore whether the employed methodology, publication type (e.g. impact factor of indexed journals and number of citations), and whether studies with a dummy versus continuous treatments differ in systematic ways. We find that studies with binary treatments report larger random effects $(0.08 \%)$ than those with continuous treatments $(0.03 \%)$. By publication type, we find larger effects for working papers $(0.09 \%$ versus $0.03 \%$ for published articles) and also larger effects for studies with less citations - both results support the suspicion that "weaker" studies overdraw the true effect of FXI, and thus should be discounted. Finally, results by type of methodology show that Regression Discontinuity

\footnotetext{
${ }^{9}$ Announced interventions are taken as those without accompanying FX operations (only announcements).
} 
Designs (15\%) and Instrumental Variables (0.9\%) have the largest effects.

Next, we examine the determinants of FX intervention effectiveness using multivariate meta-regressions. Results are reported in Table 5 and corroborate most of our previous findings. In particular, high levels of financial openness and monetary independence decrease effectiveness when run in tandem. This is consistent with the monetary trilemma, which postulates that policymakers can only gain control of the exchange rate if they either abandon monetary policy or enact capital controls. Along this line, the enactment of overall restrictions on capital flows or having a freely falling exchange rate regime increases the impact of interventions. The size of the intervention, relative to total market turnover, also increases the effects albeit by an almost negligible amount. Finally, currency crises restrict the impact of FXI. 
Table 3: Main Effects (FX Level) in Response to a \$1 Billion Net USD Purchase

\begin{tabular}{|c|c|c|c|c|c|}
\hline USD Purchases & Obs & Sample Mean & SD & $\mathrm{FE}$ & $\mathrm{RE}$ \\
\hline Total & 158 & $0.00950^{* * *}$ & 0.00357 & $0.00003^{* * *}$ & $0.00040^{* * *}$ \\
\hline \multicolumn{6}{|c|}{ Relating to the Monetary Trilemma } \\
\hline \multicolumn{6}{|l|}{ By Trilemma Measures } \\
\hline Financial Openness $>0.5$ & 96 & 0.00542 & 0.00433 & $0.00003 * * *$ & $0.00035^{* * *}$ \\
\hline Financial Openness $<0.5$ & 60 & $0.01561 * *$ & 0.00632 & $0.00010 * *$ & $0.00242^{* *}$ \\
\hline Financial Openness + Monetary Independence $>0.5$ & 74 & 0.00181 & 0.00287 & $0.00003 * * *$ & $0.00033^{* * *}$ \\
\hline Financial Openness + Monetary Independence $<0.5$ & 82 & $0.01614^{* *}$ & 0.00630 & $0.00013^{* * *}$ & $0.00159^{* * *}$ \\
\hline Departure from CIP > mean & 22 & $0.01359^{* *}$ & 0.00494 & $0.00102 * * *$ & $0.00150^{* * *}$ \\
\hline Departure from CIP $<$ mean & 100 & $0.01235^{* *}$ & 0.00476 & $0.00004^{* * *}$ & $0.00037^{* * *}$ \\
\hline \multicolumn{6}{|l|}{ By Exchange Regime } \\
\hline Currency Board & 3 & -0.00273 & 0.00285 & -0.00013 & -0.00183 \\
\hline Pre-Announced Crawling Peg & 11 & $0.01407^{*}$ & 0.00724 & 0.00046 & $0.00695^{* *}$ \\
\hline Crawling Band & 55 & $0.02582^{* * *}$ & 0.00890 & -0.00000 & $0.00091^{* *}$ \\
\hline Free Floating & 67 & -0.00125 & 0.00132 & $0.00004^{* * *}$ & $0.00040^{* * *}$ \\
\hline Freely Falling & 22 & 0.00086 & 0.00972 & 0.00008 & $0.00289^{* *}$ \\
\hline \multicolumn{6}{|l|}{ By Capital Controls } \\
\hline Restrictions on Inflows $>0.5$ & 48 & $0.03080 * * *$ & 0.00940 & -0.00000 & $0.00069^{* *}$ \\
\hline Restrictions on Inflows $<0.5$ & 99 & 0.00161 & 0.00284 & $0.00004^{* * *}$ & $0.00058^{* * *}$ \\
\hline Restrictions on Outflows $>0.5$ & 51 & $0.02482^{* * *}$ & 0.00880 & $0.00027^{* * *}$ & $0.00159^{* * *}$ \\
\hline Restrictions on Outflows $<0.5$ & 96 & 0.00387 & 0.00319 & $0.00003 * * *$ & $0.00038^{* * *}$ \\
\hline Overall Restrictions $>0.5$ & 49 & $0.03022^{* * *}$ & 0.00922 & -0.00000 & $0.00079^{* *}$ \\
\hline Overall Restrictions $<0.5$ & 98 & 0.0016 & 0.00287 & $0.00004^{* * *}$ & $0.00056^{* * *}$ \\
\hline \multicolumn{6}{|c|}{ Relating to the way FXI are conducted } \\
\hline \multicolumn{6}{|l|}{ By FX Mechanism } \\
\hline Auctions (Brazil) & 2 & 0.00185 & 0.00485 & -0.00022 & $0.00153^{* *}$ \\
\hline Auctions (Colombia) & 8 & $0.12072 * *$ & 0.04210 & $0.00864^{* * *}$ & $0.05214^{* * *}$ \\
\hline Auctions (Mexico) & 4 & 0.02305 & 0.02232 & -0.00000 & 0.02610 \\
\hline Auctions (Turkey) & 14 & $0.01136^{*}$ & 0.00611 & -0.00000 & -0.00010 \\
\hline Forwards & 3 & 0.00013 & 0.00069 & $0.00126 * * *$ & $0.00126 * * *$ \\
\hline Spot & 127 & 0.00221 & 0.00247 & $0.00004^{* * *}$ & $0.00063 * * *$ \\
\hline \multicolumn{6}{|l|}{ By Announcement } \\
\hline Announced & 4 & $0.00503^{*}$ & 0.00193 & $0.00163^{* * *}$ & $0.00298^{* * *}$ \\
\hline Secret (Dirty) & 9 & 0.00987 & 0.00869 & -0.00006 & -0.00013 \\
\hline Others & 145 & $0.00960 * *$ & 0.00386 & $0.00003 * * *$ & $0.00043^{* * *}$ \\
\hline \multicolumn{6}{|l|}{ By Intended Central Bank Objective } \\
\hline Influence FX Level & 93 & $0.00407^{* *}$ & 0.00172 & $0.00002^{* * *}$ & $0.00033^{* * *}$ \\
\hline Influence Volatility & 42 & $0.02313^{*}$ & 0.01248 & $0.00010^{*}$ & $0.00327^{* *}$ \\
\hline Influence Level \& Volatility & 8 & 0.00131 & 0.00363 & -0.00001 & -0.00048 \\
\hline Asymmetry (Sales over Total in $1^{s t}$ quartile) & 20 & -0.00549 & 0.00970 & $0.00042^{* * *}$ & 0.00025 \\
\hline Symmetry (Sales over Total in $2^{\text {nd }}$ or $3^{r d}$ quartile) & 35 & $0.01663^{* *}$ & 0.00667 & -0.00000 & $0.00034^{* *}$ \\
\hline Asymmetry (Sales over Total in $4^{t h}$ quartile) & 14 & 0.00488 & 0.00499 & $0.00801^{* * *}$ & $0.00648^{* * *}$ \\
\hline \multicolumn{6}{|l|}{ By Size of Intervention } \\
\hline Intervention Size in $1^{\text {st }}$ quartile & 19 & 0.00304 & 0.00423 & $-0.00020^{* *}$ & $-0.00168^{* *}$ \\
\hline Intervention Size in $2^{\text {nd }}$ quartile & 19 & 0.01267 & 0.02135 & $0.00002 * * *$ & $0.00033^{* * *}$ \\
\hline Intervention Size in $3^{\text {rd }}$ quartile & 16 & 0.00767 & 0.00705 & 0.00000 & $0.00037^{* *}$ \\
\hline Intervention Size in $4^{\text {th }}$ quartile & 18 & $0.03994^{* *}$ & 0.01522 & -0.00001 & 0.00066 \\
\hline
\end{tabular}

Authors' calculations. Sample means are computed by regressing effect sizes on each variable from the first column (SD is the standard deviation). FE and RE denote Fixed and Random Effects in the standard meta-analysis context. Trilemma measures are obtained from Aizenman et al. (2008), exchange rate regimes are obtained from Ilzetzki et al. (2019), and capital controls are obtained from Fernández et al. (2016). All other variables were obtained from Bloomberg, directly from each study, and from official central banks' websites (see Section 2.1). ***,**, and ${ }^{*}$ denote statistical significance at the 1,5 , and 10 percent level respectively. 
Table 4: Other Effects (FX Level) in Response to a $\$ 1$ Billion Net USD Purchase

\begin{tabular}{|c|c|c|c|c|c|}
\hline USD Purchases & Obs & Sample Mean & SD & $\mathrm{FE}$ & $\mathrm{RE}$ \\
\hline Total & 158 & $0.00950^{* * *}$ & 0.00357 & $0.00003^{* * *}$ & $0.00040^{* * *}$ \\
\hline \multicolumn{6}{|c|}{ Relating to Macroeconomic Variables } \\
\hline \multicolumn{6}{|l|}{ By GDP Classification } \\
\hline Low Income & 8 & -0.01142 & 0.01545 & $0.01114^{* * *}$ & 0.00758 \\
\hline Lower Middle Income & 21 & 0.00236 & 0.01089 & 0.00001 & 0.00059 \\
\hline Upper Middle Income & 64 & $0.02436 * * *$ & 0.00720 & 0.00000 & $0.00063 * *$ \\
\hline High Income & 65 & -0.00024 & 0.00219 & $0.00004 * * *$ & $0.00036^{* * *}$ \\
\hline \multicolumn{6}{|l|}{ By Financial Crisis } \\
\hline Systemic Banking Crisis $>10 \%$ of analyzed period & 13 & -0.00240 & 0.00306 & $0.00040^{* * *}$ & $0.00047 * * *$ \\
\hline Systemic Banking Crisis $<10 \%$ of analyzed period & 24 & $0.00420^{*}$ & 0.00218 & $0.00003^{* * *}$ & $0.00089^{* * *}$ \\
\hline Systemic Banking Crisis Intensity $>$ mean & 31 & 0.00042 & 0.00181 & $0.00003^{* * *}$ & $0.00042^{* * *}$ \\
\hline Systemic Banking Crisis Intensity $<$ mean & 6 & 0.00941 & 0.00574 & $0.00305^{* * *}$ & $0.00787 * * *$ \\
\hline Currency Crisis $>25 \%$ of analyzed period & 14 & -0.0117 & 0.01364 & -0.00000 & -0.00006 \\
\hline Currency Crisis $<25 \%$ of analyzed period & 5 & 0.00696 & 0.00934 & $0.01237^{* * *}$ & $0.01060^{* * *}$ \\
\hline \multicolumn{6}{|l|}{ By Financial Deepening } \\
\hline Financial Deepening $>$ mean & 53 & 0.00218 & 0.00135 & $0.00004^{* * *}$ & $0.00039 * * *$ \\
\hline Financial Deepening $<$ mean & 92 & $0.01525 * *$ & 0.00589 & 0.00000 & $0.00113^{* *}$ \\
\hline \multicolumn{6}{|l|}{ By Exchange Rate Volatility } \\
\hline Exchange Volatility $>$ mean & 65 & 0.00254 & 0.00660 & $0.00002^{* * *}$ & $0.00029^{* * *}$ \\
\hline Exchange Volatility $<$ mean & 93 & $0.01437^{* * *}$ & 0.00391 & $0.00003^{* * *}$ & $0.00078^{* * *}$ \\
\hline \multicolumn{6}{|l|}{ By International Reserves } \\
\hline FX Reserves > mean & 54 & 0.00469 & 0.00292 & $0.00003^{* * *}$ & $0.00051^{* * *}$ \\
\hline FX Reserves < mean & 95 & $0.01437^{* *}$ & 0.00562 & $0.00002 * *$ & $0.00064^{* *}$ \\
\hline \multicolumn{6}{|l|}{ By Sovereign Debt (in foreign currency) } \\
\hline External Debt $>$ mean & 33 & -0.00383 & 0.00730 & 0.00008 & $0.00204^{* *}$ \\
\hline External Debt $<$ mean & 48 & $0.03096 * * *$ & 0.00947 & 0.00000 & $0.00076 * *$ \\
\hline \multicolumn{6}{|l|}{ By Country's Credit Rating } \\
\hline Moodys > mean & 61 & 0.00254 & 0.00212 & $0.00004 * * *$ & $0.00041^{* * *}$ \\
\hline Moodys < mean & 82 & $0.01805^{* * *}$ & 0.00648 & -0.00000 & $0.00038^{* *}$ \\
\hline $\mathrm{S} \& \mathrm{P}>$ mean & 68 & $0.00380^{*}$ & 0.00215 & $0.00004 * * *$ & $0.00042^{* * *}$ \\
\hline $\mathrm{S} \& \mathrm{P}<$ mean & 76 & $0.01783^{* *}$ & 0.00697 & -0.00000 & $0.00034^{* *}$ \\
\hline Fitch $>$ mean & 68 & $0.00380^{*}$ & 0.00215 & $0.00004 * * *$ & $0.00042^{* * *}$ \\
\hline Fitch $<$ mean & 76 & $0.01699^{* *}$ & 0.00703 & -0.00000 & $0.00032^{* *}$ \\
\hline \multicolumn{6}{|c|}{ Relating to each Study } \\
\hline \multicolumn{6}{|l|}{ By Treatment Variable } \\
\hline Dummy & 23 & -0.00421 & 0.00863 & $0.00075^{* * *}$ & $0.00078^{* * *}$ \\
\hline No Dummy & 135 & $0.01184^{* * *}$ & 0.00389 & $0.00002^{* * *}$ & $0.00031^{* * *}$ \\
\hline \multicolumn{6}{|l|}{ By Publication Type } \\
\hline Web of Science - ISI & 67 & 0.00586 & 0.00406 & $0.00003^{* * *}$ & $0.00034 * * *$ \\
\hline Working Paper or Other & 80 & $0.01204 *$ & 0.00612 & $0.00001^{*}$ & $0.00088^{*}$ \\
\hline Impact Factor > mean & 34 & 0.01068 & 0.00703 & $0.00002^{* * *}$ & $0.00033^{*}$ \\
\hline Impact Factor $<$ mean & 33 & 0.0009 & 0.00389 & $0.00052^{* * *}$ & $0.00033^{*}$ \\
\hline No. of Citations $>$ mean & 38 & 0.01493 & 0.01041 & -0.00000 & -0.00005 \\
\hline No. of Citations $<$ mean & 120 & $0.00778^{* *}$ & 0.00338 & $0.00004 * * *$ & $0.00065^{* * *}$ \\
\hline \multicolumn{6}{|l|}{ By Methodology } \\
\hline Event Study & 6 & $0.02098^{* *}$ & 0.00745 & 0.00077 & $0.00622^{*}$ \\
\hline GARCH & 107 & 0.00450 & 0.00436 & $0.00004 * * *$ & $0.00051 * * *$ \\
\hline IV \& 2SLS & 9 & 0.01306 & 0.00720 & $0.00751^{* * *}$ & $0.00883^{* * *}$ \\
\hline OLS & 20 & 0.00929 & 0.00547 & $0.00002^{* * *}$ & $0.00069^{* * *}$ \\
\hline PSM & 5 & 0.00271 & 0.00158 & $0.00055^{* *}$ & 0.00071 \\
\hline $\mathrm{RDD}$ & 3 & $0.16296 * *$ & 0.03718 & $0.14774^{* * *}$ & $0.14774^{* * *}$ \\
\hline VAR VEC SUR & 4 & 0.01234 & 0.00966 & $0.00030 * * *$ & -0.00054 \\
\hline
\end{tabular}

Authors' calculations. Sample means are computed by regressing effect sizes on each variable from the first column (SD is the standard deviation). FE and RE denote Fixed and Random Effects in the standard meta-analysis context. Financial crises are obtained from Laeven and Valencia (2020). All other variables were obtained from Bloomberg, directly from each study, and from official central banks' websites (see Section 2.1$){ }^{* * *},{ }^{* *}$, and ${ }^{*}$ denote statistical significance at the 1,5 , and 10 percent level respectively. 
Figure 4: Forest Plot (Random Effects for FX level)

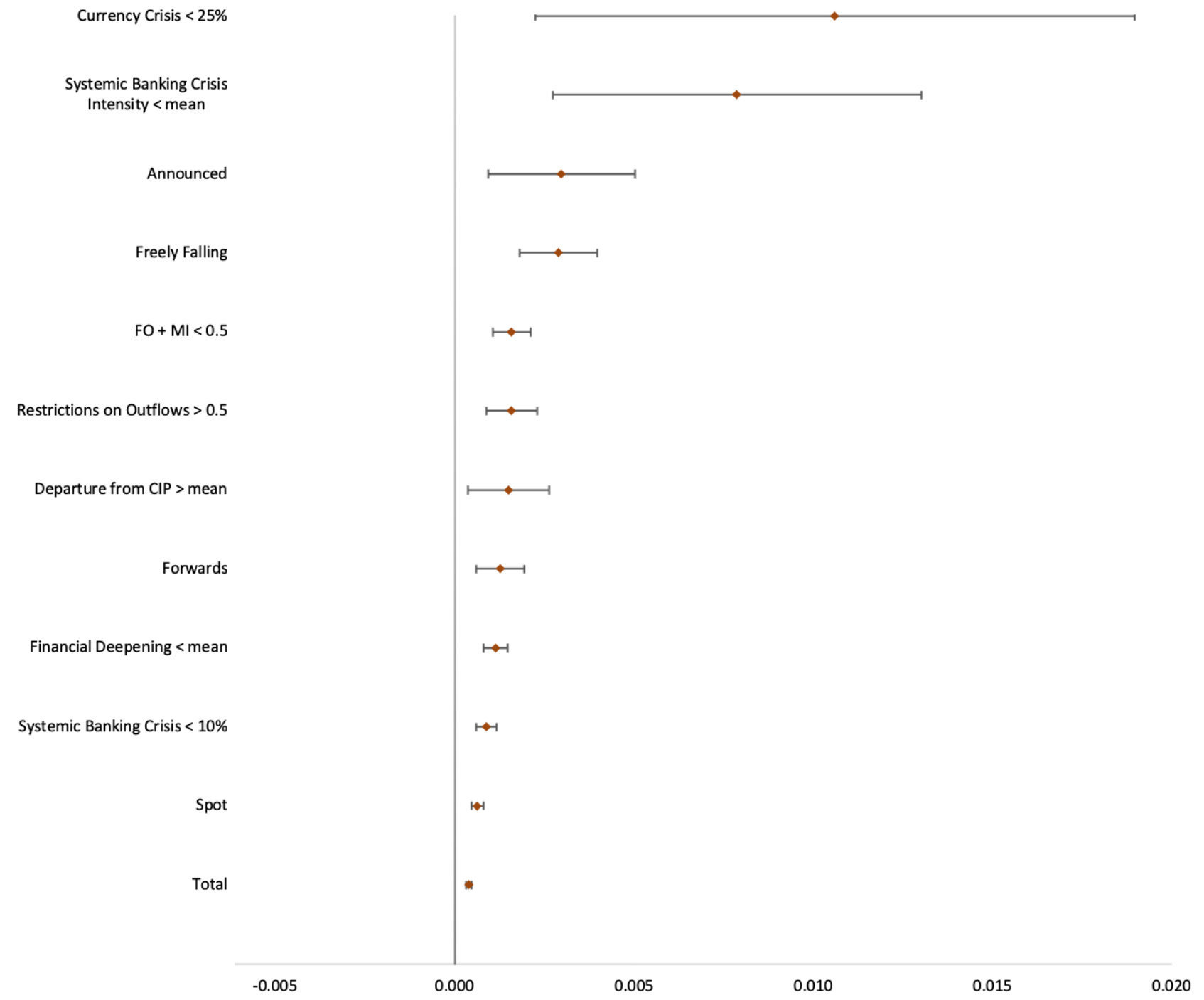

The Figure plots random effects for selected variables, sorted by magnitude. Estimations correspond to those presented in Tables 3 and 4 . Effect sizes (x-axis) are measured in exchange rate changes (\%) in response to a $\$ 1$ billion net US dollar purchase. The variables FO and MI correspond to Financial Openness and Monetary Independence. 
Table 5: Metaregression: FX Level in Response to a $\$ 1$ Billion Net USD Purchase

\begin{tabular}{|c|c|c|c|c|}
\hline VARIABLES & $\begin{array}{c}(1) \\
\text { Random Effects }\end{array}$ & $\begin{array}{c}(2) \\
\text { Random Effects }\end{array}$ & $\begin{array}{c}\text { (3) } \\
\text { Random Effects }\end{array}$ & $\begin{array}{c}(4) \\
\text { Random Effects }\end{array}$ \\
\hline $\mathrm{SE}^{2}$ & $\begin{array}{c}0.05547 \\
(0.29175)\end{array}$ & $\begin{array}{c}0.06379 \\
(0.35215)\end{array}$ & $\begin{array}{c}0.06610 \\
(0.35825)\end{array}$ & $\begin{array}{c}0.06655 \\
(0.36469)\end{array}$ \\
\hline $\mathrm{FO}+\mathrm{MI}$ & $\begin{array}{l}-0.00932^{*} \\
(0.00557)\end{array}$ & $\begin{array}{c}-0.03911^{* * *} \\
(0.01148)\end{array}$ & $\begin{array}{c}-0.03287^{* *} \\
(0.01481)\end{array}$ & $\begin{array}{c}-0.03563^{* *} \\
(0.01511)\end{array}$ \\
\hline Currency Crisis & $\begin{array}{c}-0.01748^{* *} \\
(0.00752)\end{array}$ & $\begin{array}{c}-0.03738^{* *} \\
(0.01424)\end{array}$ & $\begin{array}{c}-0.03652^{* *} \\
(0.01439)\end{array}$ & $\begin{array}{c}-0.03681^{* *} \\
(0.01462)\end{array}$ \\
\hline Freely Falling & $\begin{array}{r}0.01826^{* *} \\
(0.00799)\end{array}$ & $\begin{array}{l}0.02526^{*} \\
(0.01433)\end{array}$ & $\begin{array}{l}0.02813^{*} \\
(0.01467)\end{array}$ & $\begin{array}{l}0.02858^{*} \\
(0.01504)\end{array}$ \\
\hline Intervention Size & & $\begin{array}{l}0.00000^{*} \\
(0.00000)\end{array}$ & $\begin{array}{c}0.00000^{* * *} \\
(0.00000)\end{array}$ & $\begin{array}{c}0.00000 * * * \\
(0.00000)\end{array}$ \\
\hline Overall Capital Restrictions & & & $\begin{array}{l}0.01400^{*} \\
(0.00706)\end{array}$ & $\begin{array}{l}0.01314^{*} \\
(0.00705)\end{array}$ \\
\hline Spot & & & & $\begin{array}{c}0.00099 \\
(0.00268)\end{array}$ \\
\hline Announced & & & & $\begin{array}{c}0.00525 \\
(0.00612)\end{array}$ \\
\hline Constant & $\begin{array}{c}0.00616^{* *} \\
(0.00307)\end{array}$ & $\begin{array}{c}0.01903^{* * *} \\
(0.00510)\end{array}$ & $\begin{array}{c}0.00998 \\
(0.00807)\end{array}$ & $\begin{array}{c}0.01037 \\
(0.00835)\end{array}$ \\
\hline Observations & 156 & 78 & 59 & 59 \\
\hline
\end{tabular}

Authors' calculations. Estimates are from a full pooling least squares meta-regression, where each effect size is weighted by its inverse variance (see equation 1). Robust standard errors clustered at study-level. Variables are defined in Section 2.1 (FO and MI correspond to Financial Openness and Monetary Independence). ***, $* *$, and ${ }^{*}$ denote statistical significance at the 1,5 , and 10 percent level respectively. 


\subsection{FX Volatility}

The literature that documents effects on exchange rate volatility is narrower, and we note that there is little agreement on a standard volatility measure. In some cases, researchers employ methodologies pertaining to the Autoregressive Conditional Heteroskedasticity (ARCH) family, where the variance of the error term (i.e. FX volatility) is assumed to be serially auto-correlated. Hence, results for the variance equation are presented directly as effects on FX volatility. Studies using other methodologies generally propose their own (market-based) measure of volatility, such as the square of exchange rate changes.

Table 6 contains forest plot estimates for 121 observations and shows a reduction of FX volatility of $0.6 \%$ over the entire sample in response to a $\$ 1$ billion net dollar purchase. However, Fixed and Random-effects are almost negligible. While results are consistent with the trilemma indices, the magnitudes of the effects remain small. Again for ease in readability, in Figure 5 we depict random effects for selected variables, sorted by magnitude. In particular, RE show a greater impact when financial openness is below the mean $(-0.003 \%)$ than when above the mean $(0.001 \%)$. Also, restriction on capital inflows and outflows further reduce exchange rate volatility $(-0.004 \%$ when above the mean versus $0.001 \%$ when below).

Table 7 reports the effects on volatility based on macroeconomic variables. Notice that fewer variables have statistically significant coefficients compared to the effects on the level of the exchange rate. Among the significant variables, we find a larger reduction in volatility when: financial deepening is low, exchange rate volatility is low, sovereign debt in foreign currency is low, and credit ratings are low. In the meta-regressions presented in Table 8 we corroborate results for capital restrictions and intervention size; both of which help FXI curb exchange rate volatility. 
Table 6: Main Effects (FX Volatility) in Response to a $\$ 1$ Billion Net USD Purchase

\begin{tabular}{|c|c|c|c|c|c|}
\hline USD Purchases & Obs & Sample Mean & SD & FE & $\mathrm{RE}$ \\
\hline Total & 121 & -0.00564 & 0.00881 & $-0.00001^{* * *}$ & -0.00000 \\
\hline \multicolumn{6}{|c|}{ Relating to the Monetary Trilemma } \\
\hline \multicolumn{6}{|l|}{ By Trilemma Measures } \\
\hline Financial Openness $>0.5$ & 75 & -0.00227 & 0.00218 & $-0.00001 * * *$ & $0.00001^{*}$ \\
\hline Financial Openness $<0.5$ & 46 & -0.01111 & 0.02303 & $-0.00000^{*}$ & $-0.00003 * *$ \\
\hline Financial Openness + Monetary Independence $>0.5$ & 60 & -0.00323 & 0.00269 & $0.00000^{*}$ & $0.00001 * *$ \\
\hline Financial Openness + Monetary Independence $<0.5$ & 61 & -0.008 & 0.01734 & $-0.00001 * * *$ & $-0.00002^{* * *}$ \\
\hline Departure from CIP > mean & 19 & -0.00114 & 0.00194 & $-0.00005^{* * *}$ & -0.00001 \\
\hline Departure from CIP $<$ mean & 73 & -0.00915 & 0.01273 & -0.00000 & -0.00000 \\
\hline \multicolumn{6}{|l|}{ By Exchange Regime } \\
\hline Pre-Announced Crawling Peg & 9 & 0.06074 & 0.07792 & $-0.00001 * * *$ & $-0.00010^{* * *}$ \\
\hline Crawling Band & 34 & $-0.02576 * *$ & 0.01245 & $-0.00002 * * *$ & -0.00001 \\
\hline Free Floating & 57 & -0.01061 & 0.00788 & 0.00000 & $0.00002 * *$ \\
\hline Freely Falling & 20 & 0.0126 & 0.02595 & 0.00000 & -0.00000 \\
\hline \multicolumn{6}{|l|}{ By Capital Controls } \\
\hline Restrictions on Inflows $>0.5$ & 34 & -0.00403 & 0.02387 & $-0.00002 * * *$ & $-0.00004^{* * *}$ \\
\hline Restrictions on Inflows $<0.5$ & 73 & -0.00611 & 0.00934 & 0.00000 & 0.00001 \\
\hline Restrictions on Outflows $>0.5$ & 31 & -0.01928 & 0.02945 & $-0.00002 * * *$ & $-0.00004^{* * *}$ \\
\hline Restrictions on Outflows $<0.5$ & 76 & 0.00019 & 0.00704 & 0.00000 & 0.00001 \\
\hline Overall Restrictions $>0.5$ & 34 & -0.00403 & 0.02387 & $-0.00002 * * *$ & $-0.00004^{* * *}$ \\
\hline Overall Restrictions $<0.5$ & 73 & -0.00611 & 0.00934 & 0.00000 & 0.00001 \\
\hline \multicolumn{6}{|c|}{ Relating to the way FXI are conducted } \\
\hline \multicolumn{6}{|l|}{ By FX Mechanism } \\
\hline Auctions (Brazil) & 2 & -0.00054 & 0.02053 & $-0.02102^{* *}$ & $-0.02102 * *$ \\
\hline Auctions (Colombia) & 4 & -0.14399 & 0.07757 & -0.00012 & -0.08092 \\
\hline Auctions (Mexico) & 3 & -0.03127 & 0.03917 & 0.00000 & -0.00142 \\
\hline Auctions (Turkey) & 12 & -0.03912 & 0.03895 & -0.00000 & -0.00000 \\
\hline Forwards & 3 & -0.0765 & 0.07675 & $0.00135 * *$ & 0.00008 \\
\hline Spot & 97 & 0.00709 & 0.00858 & $-0.00001^{* *}$ & -0.00000 \\
\hline \multicolumn{6}{|l|}{ By Announcement } \\
\hline Secret (Dirty) & 7 & -0.00762 & 0.00707 & -0.00001 & -0.00003 \\
\hline Others & 113 & -0.00558 & 0.00943 & $-0.00001 * * *$ & -0.00000 \\
\hline \multicolumn{6}{|l|}{ By Intended Central Bank Objective } \\
\hline Influence FX Level & 60 & 0.00583 & 0.01169 & $-0.00001 * * *$ & 0.00000 \\
\hline Influence Volatility & 40 & -0.0265 & 0.01987 & -0.00000 & -0.00002 \\
\hline Influence Level \& Volatility & 6 & 0.0018 & 0.00385 & -0.00000 & -0.00004 \\
\hline Asymmetry (Sales over Total in $1^{\text {st }}$ quartile) & 17 & 0.01273 & 0.01489 & $0.00000^{* *}$ & 0.00000 \\
\hline Symmetry (Sales over Total in $2^{n d}$ or $3^{r d}$ quartile) & 27 & $-0.01226^{*}$ & 0.00684 & -0.00000 & -0.00002 \\
\hline Asymmetry (Sales over Total in $4^{t h}$ quartile) & 14 & -0.02593 & 0.04559 & $-0.00004^{* * *}$ & -0.00002 \\
\hline \multicolumn{6}{|l|}{ By Size of Intervention } \\
\hline Intervention Size in $1^{\text {st }}$ quartile & 16 & 0.00467 & 0.01063 & $0.00001 * * *$ & $0.00004^{* * *}$ \\
\hline Intervention Size in $2^{n d}$ quartile & 8 & 0.02428 & 0.02253 & $0.00002 * * *$ & 0.00002 \\
\hline Intervention Size in $3^{r d}$ quartile & 13 & -0.01167 & 0.00876 & $-0.00000^{* *}$ & -0.00000 \\
\hline Intervention Size in $4^{\text {th }}$ quartile & 14 & -0.0282 & 0.02598 & 0.00000 & -0.00000 \\
\hline
\end{tabular}

Authors' calculations. Sample means are computed by regressing effect sizes on each variable from the first column (SD is the standard deviation). FE and RE denote Fixed and Random Effects in the standard metaanalysis context. Trilemma measures are obtained from Aizenman et al. (2008), exchange rate regimes are obtained from Ilzetzki et al. (2019), and capital controls are obtained from Fernández et al. (2016). All other variables were obtained from Bloomberg, directly from each study, and from official central banks' websites (see Section 2.1). ${ }^{* * *},{ }^{* *}$, and ${ }^{*}$ denote statistical significance at the 1,5 , and 10 percent level respectively. 
Table 7: Other Effects (FX Volatility) in Response to a $\$ 1$ Billion Net USD Purchase

\begin{tabular}{|c|c|c|c|c|c|}
\hline USD Purchases & Obs & Sample Mean & SD & FE & $\mathrm{RE}$ \\
\hline Total & 121 & -0.00564 & 0.00881 & $-0.00001^{* * *}$ & $-0.00000^{* * *}$ \\
\hline \multicolumn{6}{|c|}{ Relating to Macroeconomic Variables } \\
\hline \multicolumn{6}{|l|}{ By GDP Classification } \\
\hline Low Income & 6 & -0.01214 & 0.08573 & $-0.00001 *$ & -0.00626 \\
\hline Lower Middle Income & 18 & 0.03745 & 0.03958 & $-0.00000^{* *}$ & $-0.00002 * *$ \\
\hline Upper Middle Income & 44 & $-0.02757^{*}$ & 0.01375 & $-0.00002 * * *$ & -0.00001 \\
\hline High Income & 53 & -0.00132 & 0.00221 & 0.00000 & $0.00001 * *$ \\
\hline \multicolumn{6}{|l|}{ By Financial Crisis } \\
\hline Systemic Banking Crisis $>10 \%$ of analyzed period & 13 & $0.00246^{* *}$ & 0.00097 & -0.00000 & 0.00000 \\
\hline Systemic Banking Crisis $<10 \%$ of analyzed period & 11 & 0.0027 & 0.04223 & $-0.00000 * *$ & 0.00000 \\
\hline Systemic Banking Crisis Intensity $>$ mean & 19 & -0.00149 & 0.00212 & -0.00000 & 0.00000 \\
\hline Systemic Banking Crisis Intensity $<$ mean & 5 & 0.01802 & 0.09830 & $-0.00000 * *$ & 0.00184 \\
\hline Currency Crisis $>25 \%$ of analyzed period & 12 & 0.0111 & 0.01577 & 0.00000 & 0.00000 \\
\hline Currency Crisis $<25 \%$ of analyzed period & 5 & 0.01802 & 0.09830 & -0.00000 & 0.00184 \\
\hline \multicolumn{6}{|l|}{ By Financial Deepening } \\
\hline Financial Deepening $>$ mean & 52 & 0.00034 & 0.00138 & $0.00000^{*}$ & $0.00001 * *$ \\
\hline Financial Deepening $<$ mean & 69 & -0.01014 & 0.01544 & $-0.00001 * * *$ & $-0.00002 * * *$ \\
\hline \multicolumn{6}{|l|}{ By Exchange Rate Volatility } \\
\hline Exchange Volatility $>$ mean & 50 & -0.0031 & 0.00539 & $0.00000 * * *$ & $0.00001^{* * *}$ \\
\hline Exchange Volatility $<$ mean & 71 & -0.00742 & 0.01457 & $-0.00001 * * *$ & $-0.00001^{*}$ \\
\hline \multicolumn{6}{|l|}{ By International Reserves } \\
\hline FX Reserves > mean & 26 & -0.02414 & 0.01657 & $-0.00000^{* *}$ & 0.00000 \\
\hline FX Reserves $<$ mean & 84 & -0.0014 & 0.01157 & $-0.00001^{* * *}$ & -0.00001 \\
\hline \multicolumn{6}{|l|}{ By Sovereign Debt (in foreign currency) } \\
\hline External Debt $>$ mean & 27 & -0.0152 & 0.02586 & -0.00000 & -0.00000 \\
\hline External Debt $<$ mean & 37 & -0.00544 & 0.02193 & $-0.00003^{* * *}$ & $-0.00004^{* * *}$ \\
\hline \multicolumn{6}{|l|}{ By Country's Credit Rating } \\
\hline Moodys > mean & 46 & -0.00291 & 0.00220 & 0.00000 & $0.00001 *$ \\
\hline Moodys $<$ mean & 58 & -0.00929 & 0.01641 & $-0.00001 * * *$ & $-0.00002^{* * *}$ \\
\hline $\mathrm{S} \& \mathrm{P}>$ mean & 46 & -0.00291 & 0.00220 & 0.00000 & $0.00001 *$ \\
\hline $\mathrm{S} \& \mathrm{P}<$ mean & 59 & -0.00914 & 0.01613 & $-0.00001 * * *$ & $-0.00002^{* * *}$ \\
\hline Fitch $>$ mean & 46 & -0.00291 & 0.00220 & 0.00000 & $0.00001 *$ \\
\hline Fitch $<$ mean & 59 & -0.0119 & 0.01634 & $-0.00001 * * *$ & $-0.00002^{* * *}$ \\
\hline \multicolumn{6}{|c|}{ Relating to each Study } \\
\hline \multicolumn{6}{|l|}{ By Treatment Variable } \\
\hline Dummy & 17 & 0.00117 & 0.01489 & -0.00000 & -0.00001 \\
\hline No Dummy & 104 & -0.00675 & 0.00997 & $-0.00001 * * *$ & -0.00000 \\
\hline \multicolumn{6}{|l|}{ By Publication Type } \\
\hline Web of Science - ISI & 66 & -0.00503 & 0.00401 & $-0.00001 * * *$ & -0.00000 \\
\hline Working Paper or Other & 52 & -0.00672 & 0.01997 & $-0.00000^{*}$ & 0.00000 \\
\hline Impact Factor $>$ mean & 41 & $-0.00808^{*}$ & 0.00464 & $-0.00001 * * *$ & -0.00001 \\
\hline Impact Factor < mean & 32 & 0 & 0.00000 & $0.00000^{* * *}$ & 0.00001 \\
\hline Citations > mean & 36 & -0.00423 & 0.00440 & $0.00000^{*}$ & $0.00002 * *$ \\
\hline Citations $<$ mean & 85 & -0.00623 & 0.01242 & $-0.00001 * * *$ & -0.00001 \\
\hline \multicolumn{6}{|l|}{ By Methodology } \\
\hline Event Study & 2 & -0.10694 & 0.02417 & $-0.11667^{* * *}$ & $-0.11667^{* * *}$ \\
\hline GARCH & 92 & 0.00076 & 0.01055 & $-0.00001 * * *$ & -0.00000 \\
\hline IV \& 2SLS & 2 & $-0.02000^{* *}$ & 0.00107 & $-0.01998^{* * *}$ & $-0.01998 * * *$ \\
\hline OLS & 15 & -0.00789 & 0.01407 & -0.00030 & -0.00033 \\
\hline PSM & 4 & -0.00001 & 0.00006 & -0.00003 & -0.00004 \\
\hline VAR VEC SUR & 5 & -0.00354 & 0.00363 & 0.00000 & 0.00004 \\
\hline
\end{tabular}

Authors' calculations. Sample means are computed by regressing effect sizes on each variable from the first column (SD is the standard deviation). FE and RE denote Fixed and Random Effects in the standard meta-analysis context. Financial crises are obtained from Laeven and Valencia (2020). All other variables were obtained from Bloomberg, directly from each study, and from official central banks' websites (see Section 2.1 ). ${ }^{* * *}, * *$, and ${ }^{*}$ denote statistical significance at the 1,5 , and 10 percent level respectively. 


\section{Figure 5: Forest Plot (Random Effects for FX Volatility)}

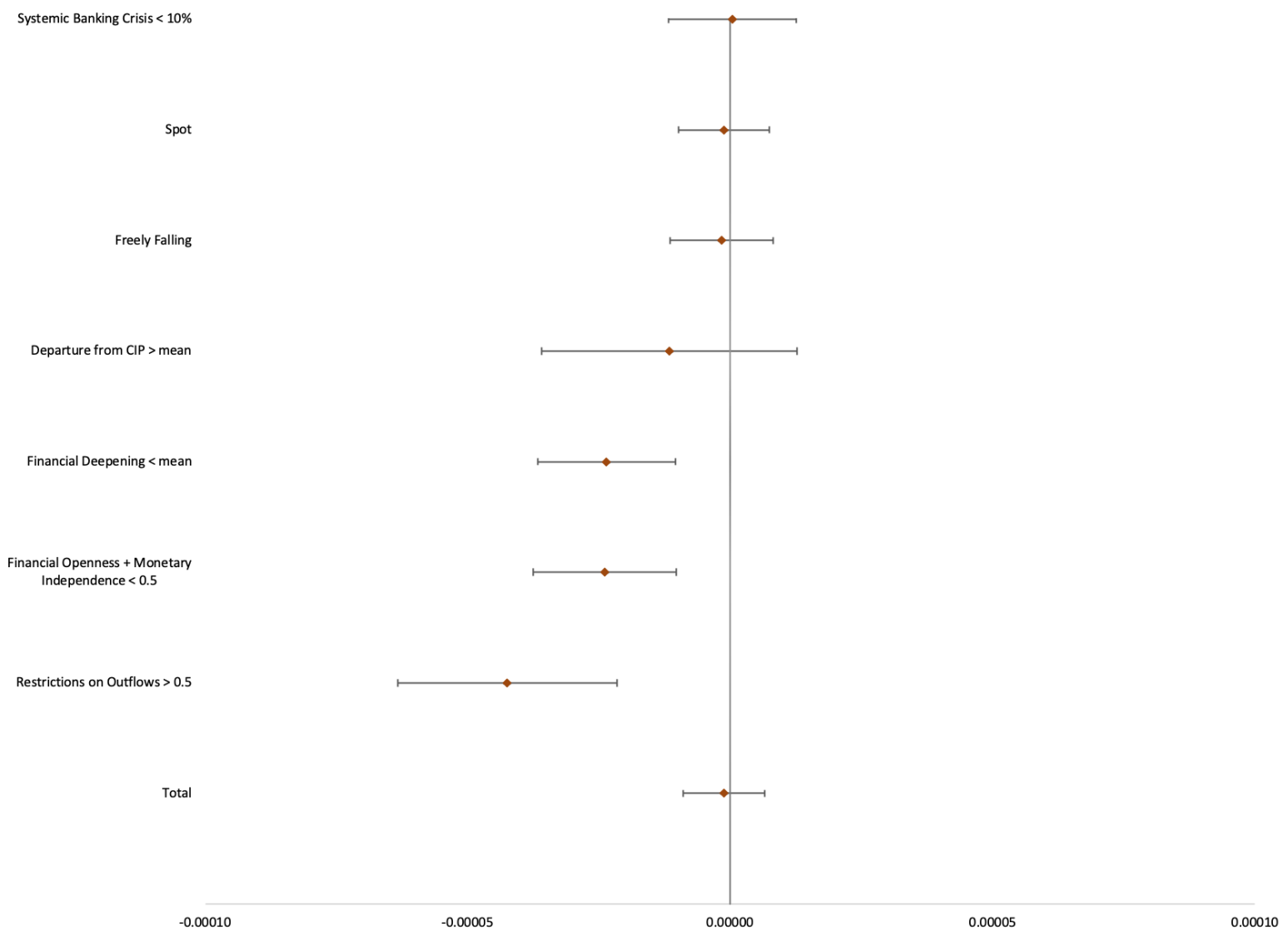

The Figure plots random effects for selected variables, sorted by magnitude. Estimations correspond to those presented in Tables 6 and 7 . Effect sizes (x-axis) are measured in exchange rate changes (\%) in response to a $\$ 1$ billion net US dollar purchase. 
Table 8: Metaregression: FX Volatility in Response to a $\$ 1$ Billion Net USD Purchase

\begin{tabular}{lcccc}
\hline \multirow{2}{*}{ VARIABLES } & $(1)$ & $(2)$ & $(3)$ & $(4)$ \\
$\mathrm{SE}^{2}$ & Random Effects & Random Effects & Random Effects & Random Effects \\
& -1.94710 & -1.96831 & -1.99233 & -1.99207 \\
$\mathrm{FO}+\mathrm{MI}$ & $(3.35152)$ & $(4.75784)$ & $(4.76295)$ & $(4.80904)$ \\
& 0.00026 & 0.00064 & 0.00011 & 0.00012 \\
Currency Crisis & $(0.00018)$ & $(0.00039)$ & $(0.00019)$ & $(0.00021)$ \\
& -0.00000 & 0.00060 & 0.00057 & 0.00057 \\
Freely Falling & $(0.00010)$ & $(0.00045)$ & $(0.00043)$ & $(0.00044)$ \\
& 0.00005 & -0.00040 & -0.00052 & -0.00051 \\
Intervention Size & $(0.00015)$ & $(0.00046)$ & $(0.00044)$ & $(0.00044)$ \\
& & -0.00000 & $-0.00000^{* * *}$ & $-0.00000^{* *}$ \\
Overall Capital Restrictions & & $(0.00000)$ & $(0.00000)$ & $(0.00000)$ \\
& & & $-0.00021^{*}$ & $-0.00021^{*}$ \\
Spot & & & $(0.00011)$ & $(0.00012)$ \\
& & & & 0.00000 \\
Constant & & $-0.00031^{*}$ & -0.00001 & $-0.00002)$ \\
& -0.00013 & $(0.00019)$ & $(0.00012)$ & $(0.00013)$ \\
Observations & $(0.00010)$ & & & 43 \\
\hline
\end{tabular}

Authors' calculations. Estimates are from a full pooling least squares meta-regression, where each effect size is weighted by its inverse variance (see equation 1). Robust standard errors clustered at study-level. Variables are defined in Section 2.1 (FO and MI correspond to Financial Openness and Monetary Independence). ***, **, and ${ }^{*}$ denote statistical significance at the 1,5 , and 10 percent level respectively.

\section{Publication Bias and Robustness Checks}

\subsection{Publication Bias}

We next examine whether there is evidence of a publication selection bias, which exists when editors, referees, or researchers are inclined towards statistically significant results, often overstating the magnitude of the results. In Figure 6 we depict the corresponding funnel plots for the level and volatility of the exchange rate, under the fixed effects assumption. Regarding the level, Figure 6a, shows that a few observations lie within the shaded region (mostly to the right of the mean) which in principle suggests a positive bias towards exchange rate depreciation. However, publication bias, if any, seems to be small. Alternatively, Figure $6 \mathrm{~b}$ does not exhibit evidence of publication bias for exchange rate volatility.

We formally test for the existence of a bias and show results in Table 9 . Columns 2 and 5 correspond to weighted regressions where the constant matches the overall fixed effects, for the level and volatility of the exchange rate, respectively. Columns 3 and 6 report estimates of the "precision-effect test" known as the Funnel Plot Asymmetry Test (FAT-PET), based on the weighted least squares regression of equation 2. For the level of the exchange rate (left panel), the test rejects the null of a symmetric funnel (i.e. $\beta_{0}=0$ ). Nonetheless, column 4 reports the "precision-effect estimate with standard error test" (PEESE), which according 
to Stanley (2001), corrects for the possible bias in the FAT-PET results. It shows that the estimated effect size is nearly identical to the bias-corrected effect. Consequently, while there is evidence of a publication bias, it is sufficiently small so as not to alter the estimates that follow from meta-regressions.

Figure 6: Testing for Publication Selection Bias

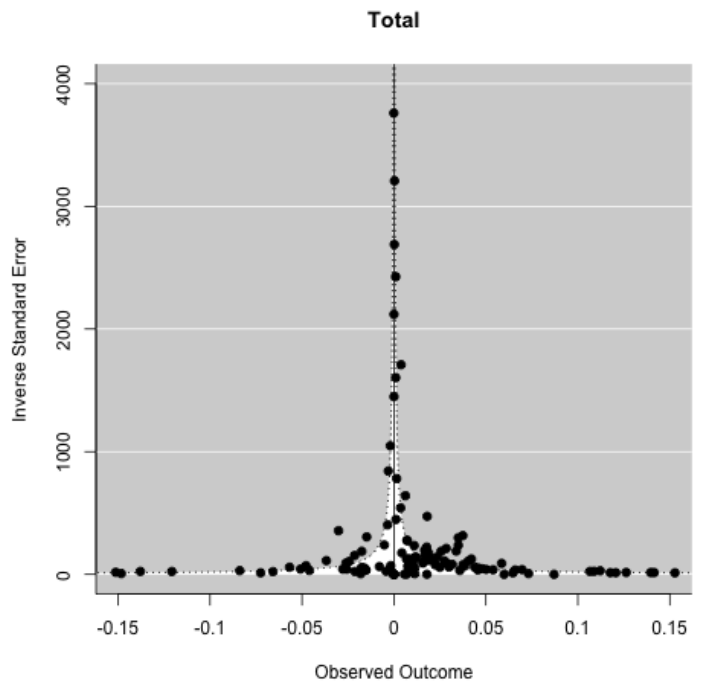

(a) FX Level

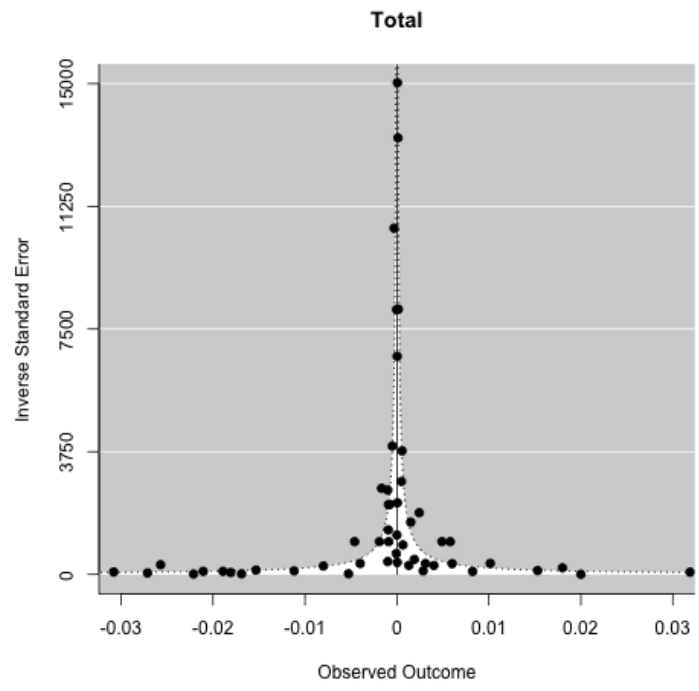

(b) FX Volatility

The two figures (funnels) plot effect sizes (x-axis) against the inverse of their corresponding standard errors (y-axis). Intuitively, results with high variance should scatter at the bottom, while high precision effects should bunch together around the mean. Hence, observations in the shaded region indicate evidence of publication bias.

Table 9: Publication Bias (FX Level \& FX Volatility)

\begin{tabular}{lcccccc}
\hline & \multicolumn{3}{c}{ FX Level } & \multicolumn{3}{c}{ FX Volatility } \\
VARIABLES & WLS & FAT-PET & PEESE & WLS & FAT-PET & PEESE \\
\hline \multirow{3}{*}{$\mathrm{SE}$} & & $1.08806^{* * *}$ & & & -0.01482 & \\
& & $(0.32498)$ & & & $(0.28499)$ & \\
$\mathrm{SE}^{2}$ & & & 0.07482 & & & -1.94711 \\
& & & $(0.04975)$ & & & $(2.67198)$ \\
Constant & $0.00003^{*}$ & 0.00001 & $0.00003^{*}$ & -0.00001 & -0.00001 & -0.00001 \\
& $(0.00001)$ & $(0.00001)$ & $(0.00001)$ & $(0.00001)$ & $(0.00001)$ & $(0.00001)$ \\
& & & & & & 121 \\
Observations & 158 & 158 & 158 & 121 & 121 \\
R-squared & 0.00000 & 0.09548 & 0.00006 & 0.00000 & 0.00001 & 0.00087 \\
\hline
\end{tabular}

Authors' calculations. The dependent variable corresponds to the effect size and reported estimates follow the specification of equation 2 (for FAT-PET) and 3 (PEESE). Robust standard errors are in parenthesis and clustered at study-level. ${ }^{* * *},{ }^{* *}$, and $*$ denote statistical significance at the 1,5 , and 10 percent level respectively. 


\subsection{Robustness Checks}

We conducted several robustness checks. First, we estimated separate exercises for purchases and sales of foreign currency, whenever each study explicitly allowed for this distinction. Overall, we obtain very similar results, namely a $0.9 \%$ depreciation for purchases (Tables B1 and B2 and a 1.0\% appreciation for sales (Tables B3 and B4) after a $\$ 1$ billion dollar intervention.

In Tables $\mathrm{C5}$ and $\mathrm{C6}$ we aggregate effects (per study) into one synthetic effect size in order to control for multiple results carried out by a given investigation. Thus, if for example a study reports 5 findings, each finding is given a weight of $20 \%$. Notice that the number of observations decreases from 158 to 68 . On average, we record 3 findings per study, with a standard deviation of 4 findings. Results are again very similar and show an average depreciation of domestic currency of $0.9 \%$ in response to a $\$ 1$ billion net dollar purchase. Under RE without covariates, we find the same depreciation of $0.04 \%$.

Finally, in Tables D7 and D8 we replicate our benchmark results but focus only on studies that use daily frequency data in order to evaluate the extent to which studies that use low frequency data influence our results. Results are very similar to our benchmark findings of Section 4.1 , in part due to the fact that $84 \%$ of studies already used daily information.

\section{Conclusion}

In this paper we present the first comprehensive meta-analysis on the effects of foreign exchange intervention, with 279 reported effects, stemming from 74 distinct studies. It covers estimations conducted on 19 countries and during 5 decades. We find an average depreciation of domestic currency of $1 \%$ and -for the first time in this literature- a reduction of exchange rate volatility of $0.6 \%$, in response to a $\$ 1$ billion US dollar purchase. These results are statistically highly significant and we show that they hold when controlling for publication bias. Thus, our results indicate the potential power of foreign exchange interventions.

While this key result holds through all kinds of checks, the above given impact numbers require some qualification. Most important, they are calculated numbers; impacts are measured with true intervention volumes with a median of $\$ 93$ dollars and then linearly inflated up to one billion USD ${ }^{10}$ Thus it remains unclear whether the calculated size of

\footnotetext{
${ }^{10}$ Nonetheless, the mean intervention volume is $\$ 600$ million dollars with a standard deviation of $\$ 1$ billion.
} 
impact can be realized. Another qualification is the equal weighting of primary studies, while the meta-analysis treats studies differently and gives more weight to larger studies which are seen as more reliable. For the discussion of results we thus rely on the Random Effects estimations, which we regard as most appropriate. These estimates confirm some former findings on foreign exchange interventions which can be regarded as stylized facts, but they also provide new insights.

Stylized facts are documented by Fratzscher et al. (2019) in their study of sterilized foreign exchange interventions covering 33 countries. We confirm, first, that announced interventions are more powerful than secret ones (even though the measurement differs between these studies). Second, large intervention volumes are supportive for success, in our case the impact is more than two times larger if volumes (relative to market size) are within the top $50 \%$ percent compared to the bottom $50 \%$.

Beyond this confirmation we are able to provide three further new results, two of which are related to the consideration of macroeconomic variables (see Table 4): first, intervention effects are larger in emerging countries (and possibly also developing countries) than in advanced economies. This is not really surprising, as it is known that central banks in emerging countries intervene with larger volumes relative to the size of their foreign exchange markets. Due to the related institutional circumstances it is thus expected that less financial deepening and higher (foreign currency) sovereign debt are also linked to higher intervention effectiveness. Second, and this is new, we see from the consideration of crises situations (although a relatively small number of observations) that foreign exchange intervention effectiveness seems to be higher in circumstances where banking or currency crises are less severe.

The third new result is derived from our combination of foreign exchange interventions with information about the monetary trilemma, i.e. the conflict between monetary independence, financial openness and exchange rate stability. In this policy setting foreign exchange interventions are seen as instrument to improve exchange rate stability. We find indeed that interventions work much more effectively with less financial openness, and also if we form a combination of less openness with limited monetary independence. While this is not new per se, we are not aware that it has been shown in a systematic empirical study like ours.

We believe that our work can be useful for central bankers, especially those enacting foreign exchange interventions. The most important lesson is that we confirm for the large set of studies under inspection that foreign exchange interventions are -in general- able to 
impact the exchange rate in the intended way, i.e. regarding its level (or direction) and its volatility, the former better than the latter. While this result is robust, there are still three important caveats to be considered for policy makers:

1. The empirical evidence may be plagued by selection bias because central banks do not intervene randomly but choose situations with higher probability of success.

2. Intervention success is enhanced if the "trilemma conditions" are met, i.e. if policy is willing to give less weight to competing objectives, i.e. either to limit financial openness (e.g. by allowing capital controls) or monetary independence.

3. Intervention success is supported by proper execution, i.e. by announcing interventions and by implementing this by high intervention volumes.

Overall, there are good reasons why central banks, less so in advanced economies, use the instrument of foreign exchange interventions. 


\section{Bibliography}

Adler, G., N. Lisack, And R. C. Mano (2019): "Unveiling the effects of foreign exchange intervention: a panel approach," Emerging Markets Review, 40, 100620.

Aguilar, J. AND S. Nydahl (2000): "Central bank intervention and exchange rates: the case of Sweden," Journal of International Financial Markets, Institutions and Money, 10, 303-322.

Aizenman, J., M. D. Chinn, And H. Ito (2008): "Assessing the emerging global financial architecture: measuring the trilemma's configurations over time," Working Paper 14533, National Bureau of Economic Research.

Beine, M., A. BÉnAssy-Quéré, and C. Lecourt (2002): "Central bank intervention and foreign exchange rates: new evidence from FIGARCH estimations," Journal of International Money and Finance, 21, $115-144$.

Blanchard, O., G. Adler, and I. de Carvalho Filho (2015): "Can foreign exchange intervention stem exchange rate pressures from global capital flow shocks?" NBER Working Papers 21427, National Bureau of Economic Research, Inc.

Brause, A. (2008): "Foreign exchange interventions in emerging market countries: new lessons from Argentina," W.E.P. - Würzburg Economic Papers 79, University of Würzburg, Chair for Monetary Policy and International Economics.

Broto, C. (2013): "The effectiveness of forex interventions in four Latin American countries," Emerging Markets Review, 17, 224-240.

Brychka, S., D. Klynovskyi, D. Krukovets, And A. Oharkov (2019): "Meta-analysis: effect of FX interventions on the exchange rate," Modern Economic Studies, 2, 24-44.

Castrén, O. (2004): "Do options-implied RND functions on G3 currencies move around the times of interventions on the JPY/USD exchange rate?" Working Paper Series 410, European Central Bank.

Chamon, M., D. Hofman, N. Magud, and A. Werner (2019a): Chapter 4: the effectiveness of intervention, USA: International Monetary Fund.

— (2019b): Chapter 9: learning from experience in Colombia, USA: International Monetary Fund.

Dominguez, K. (1998): "Central bank intervention and exchange rate volatility," Journal of International Money and Finance, 17, 161-190.

Dominguez, K. M. (1993): "Does central bank intervention increase the volatility of foreign exchange rates?" NBER Working Papers 4532, National Bureau of Economic Research, Inc.

(2006): "When do central bank interventions influence intra-daily and longer-term exchange rate movements?" Journal of International Money and Finance, 25, 1051-1071.

Dominguez, K. M. And J. A. Frankel (1993): "Does foreign-exchange intervention matter? the portfolio effect," American Economic Review, 83, 1356-69.

Dornbusch, R. (1980): "Exchange rate economics: where do we stand?" Brookings Papers on Economic Activity, 11, 143-206.

Echavarría, J. J., L. F. Melo, and M. Villamizar (2014): "The impact of foreign exchange intervention in Colombia. An event study approach," Revista Desarrollo y Sociedad. 
Echavarría, J. J., D. VÁsquez, and M. Villamizar (2010): "Impacto de las intervenciones cambiarias sobre el nivel y la volatilidad de la tasa de cambio en Colombia," ENSAYOS SOBRE POLÍTICA ECONÓMICA.

EDISON, H. (1993): "The effectiveness of central-bank intervention: a survey of the literature after 1982," Princeton Studies in International Economics, International Economics Section, Departement of Economics Princeton University, 18, International Economics Section, Departement of Economics Princeton University,.

Edison, H., P. Cashin, And H. Liang (2006): "Foreign exchange intervention and the Australian dollar: has it mattered?" International Journal of Finance 83 Economics, 11, 155-171.

Egert, B. And M. LAng (2005): "Foreign exchange interventions in Croatia and Turkey: should we give a Damn?" William Davidson Institute Working Papers Series wp755, William Davidson Institute at the University of Michigan.

Fernández, A., M. W. Klein, A. Rebucci, M. Schindler, And M. Uribe (2016): "Capital control measures: a new dataset," IMF Economic Review, 64, 548-574.

Frankel, J. (2016): The Plaza Accord, 30 years later, Washington: Peterson Institute for International Economics.

Fratzscher, M., O. Gloede, L. Menkhoff, L. Sarno, and T. Stöhr (2019): "When is foreign exchange intervention effective? evidence from 33 countries," American Economic Journal: Macroeconomics, 11, $132-156$.

Frenkel, M., C. Pierdzioch, and G. Stadtmann (2005): "The effects of Japanese foreign exchange market interventions on the yen/U.S. dollar exchange rate volatility," International Review of Economics ES Finance, 14, 27-39.

Ghosh, A. R., J. D. Ostry, And M. S. Qureshi (2018): Taming the tide of capital flows: a policy guide, vol. 1 of MIT Press Books, The MIT Press.

Hoshikawa, T. (2008): "Does foreign exchange intervention reduces the exchange rate volatility?" Applied Financial Economics Letters, 4, 221-224.

Ilzetzki, E., C. M. Reinhart, And K. S. Rogoff (2019): "Exchange arrangements entering the Twenty-First Century: Which anchor will hold?" The Quarterly Journal of Economics, 134, 599-646.

Katusime, L. And F. W. AgBola (2018): "Modelling the impact of central bank intervention on exchange rate volatility under inflation targeting," Applied Economics, 50, 4373-4386.

Keefe, H. G. And E. W. Rengifo (2015): "Options and central bank currency market intervention: the case of Colombia," Emerging Markets Review, 23, 1-25.

Kitamura, Y. (2017): "A stopping time approach to assessing the effectiveness of foreign exchange intervention: an application to Japanese data," Journal of International Money and Finance, 75, 32-46.

KNAPP, G. AND J. HARTUNG (2003): "Improved tests for a random effects meta-regression with a single covariate," Statistics in medicine, 22, 2693-710.

Kriljenko, J. I. C., C. Karacadag, R. P. Guimarães, and S. Ishit (2006): "Official foreign exchange intervention," IMF Occasional Papers 249, International Monetary Fund.

Kuersteiner, G., D. Phillips, and M. Villamizar-Villegas (2018): "Effective sterilized foreign exchange intervention? Evidence from a rule-based policy," Journal of International Economics, 113, $118-138$ 
Laeven, L. and F. Valencia (2020): "Systemic banking crises database II," IMF Economic Review, 68, $307-361$.

Lipsey, M. W. And D. B. Wilson (2001): Practical meta-analysis., vol. 49 of Applied social research methods series, Sage Publications, Inc.

Menkhoff, L. (2013): "Foreign exchange intervention in emerging markets: a survey of empirical studies," The World Economy, 36, 1187-1208.

Menkhoff, L., M. Rieth, And T. Stöhr (2020): "The dynamic impact of FX interventions on financial markets," Review of Economics and Statistics, Forthcoming.

Neely, C. J. (2005): "An analysis of recent studies of the effect of foreign exchange intervention," Review, $685-718$.

Onder, Y. K. And M. Villamizar-Villegas (2018): "The effects of monetary and exchange rate policy shocks: evidence from an emerging market economy," International Journal of Central Banking, 14, 159-199.

SARno, L. And M. P. TAYlor (2001): "Official intervention in the foreign exchange market: is it effective and, if so, how does it work?" Journal of Economic Literature, 39, 839-868.

Stanley, T. and H. Doucouliagos (2012): "Meta-regression analysis in economics and business," MetaRegression Analysis in Economics and Business, 5, 1-190.

Stanley, T. D. (2001): "Wheat from chaff: meta-analysis as quantitative literature review," Journal of Economic Perspectives, 15, 131-150.

Stanley, T. D. and H. Doucouliagos (2011): "Meta-regression approximations to reduce publication selection bias," Working Papers 2011-4, Deakin University, Department of Economics.

Stanley, T. D. And S. B. Jarrell (1989): "Meat-regression analysis: a quantitative method of literature surveys," Journal of Economic Surveys, 3, 161-170.

Tobal, M. and Y. Renato (2016): "Two models of FX market interventions: the cases of Brazil and Mexico," Working Papers 2016-14, Banco de México.

Trivedi, S. R. And P. G. Apte (2016): "Central bank intervention in USD/INR market: estimating its reaction function and impact on volatility," Asia-Pacific Financial Markets, 23, 263-279.

Utsunomiya, T. (2013): "A new approach to the effect of intervention frequency on the foreign exchange market: evidence from Japan," Applied Economics, 45, 3742-3759.

Vargas-Herrera, H. And M. Villamizar-Villegas (2019): "Effectiveness of FX intervention and the flimsiness of exchange rate expectations," Borradores de Economia 1070, Banco de la Republica de Colombia.

Villamizar-Villegas, M. And D. Perez-Reyna (2017): "A theoretical approach to sterilized foreign exchange intervention," Journal of Economic Surveys, 31, 343-365.

Vooren, M., C. Haelermans, W. Groot, and H. Maassen van den Brink (2019): "The effectiveness of active labor market policies: a meta-analysis," Journal of Economic Surveys, 33, 125-149. 


\section{Appendix A Trilemma characterization for selected countries}

Figure A1: Trilemma Indices as in Aizenman et al. (2008) for selected countries

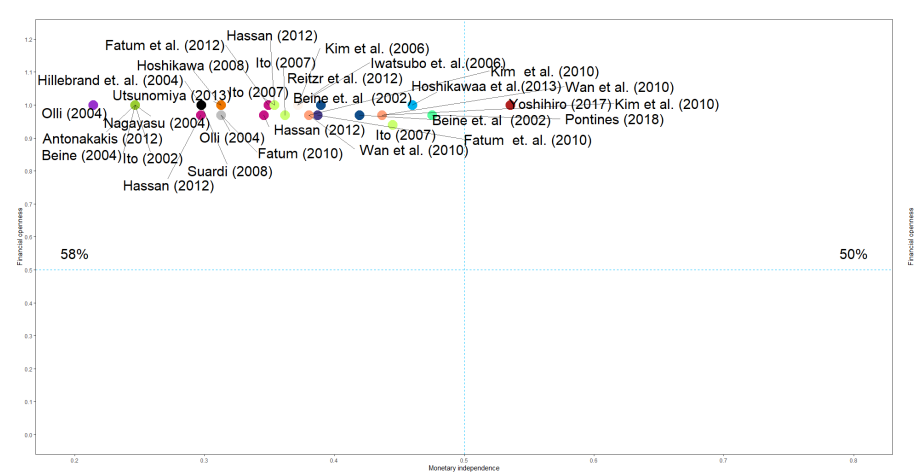

(a) Japan

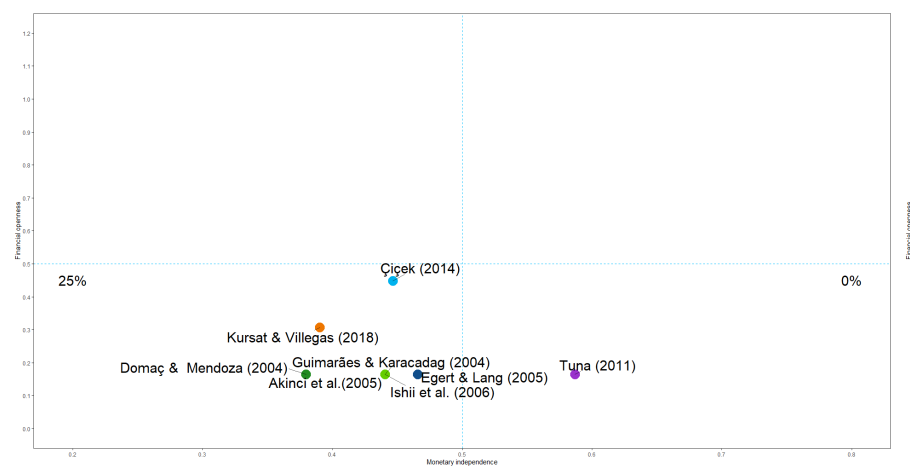

(c) Turkey

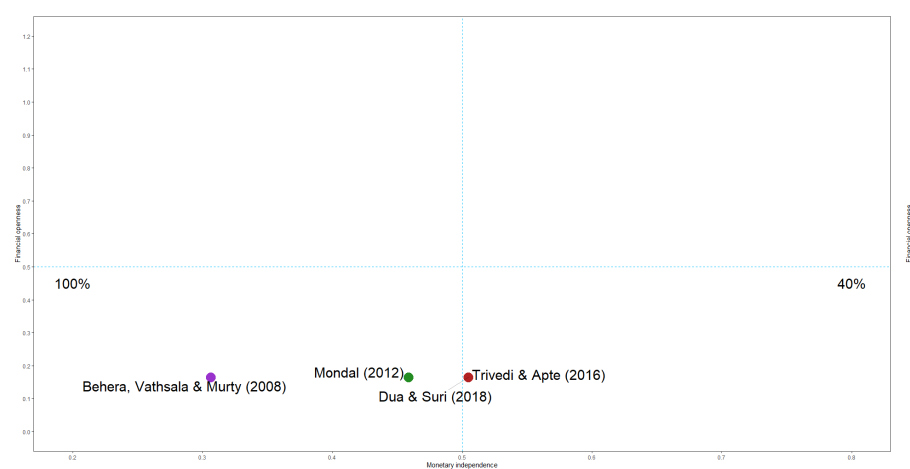

(e) India

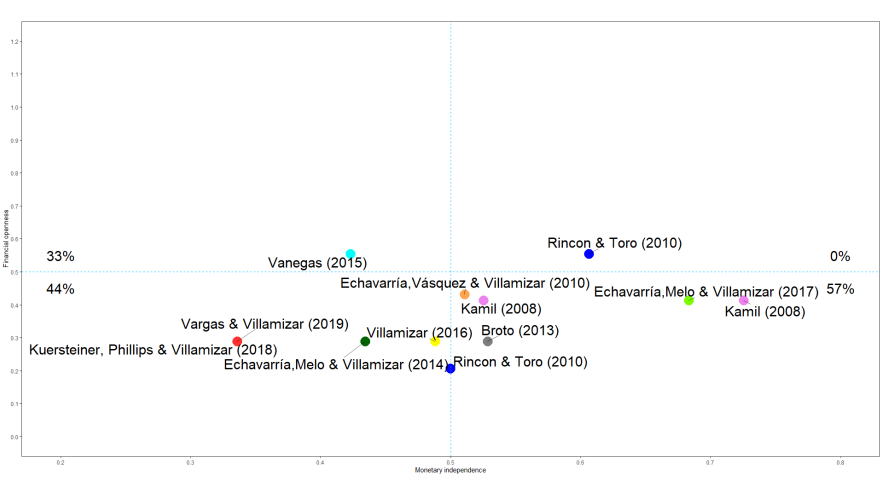

(b) Colombia

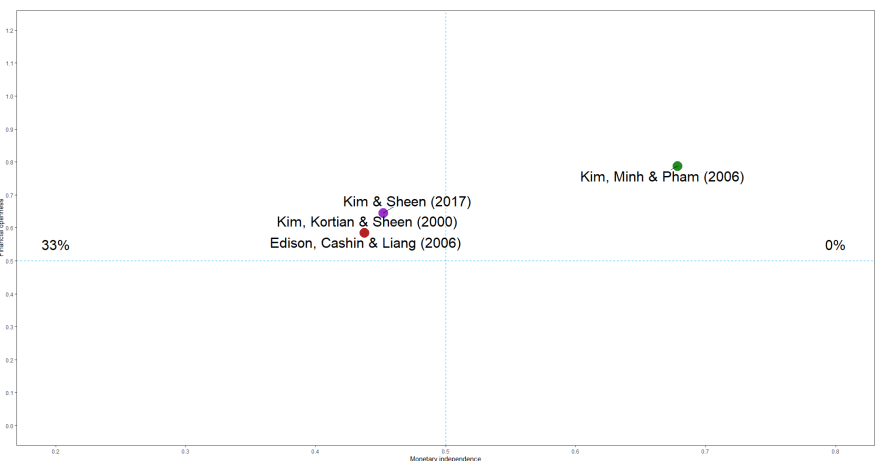

(d) Australia

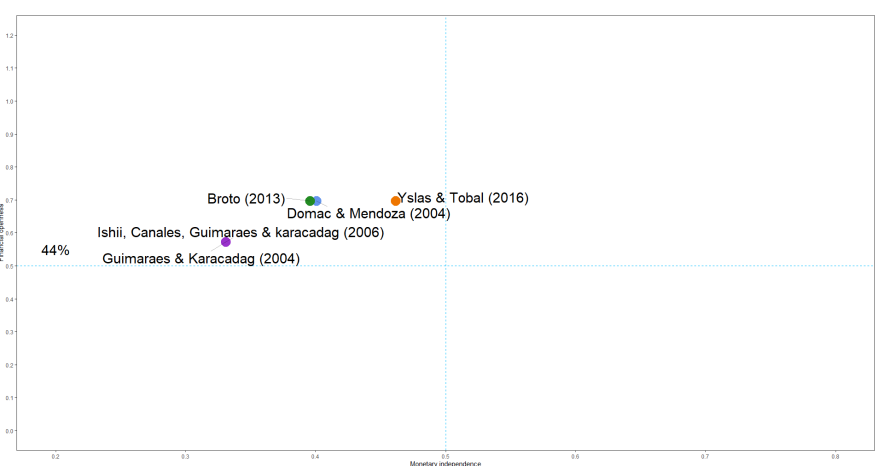

(f) Mexico

The Figure plots our surveyed studies grouped by country and by decade, and categorized by the trilemma indices proposed in Aizenman et al. (2008), namely the degree of financial openness (y-axis) and monetary autonomy (x-axis). In theory, the top right quadrant is more prone to the monetary trilemma. The values (in \%) denote the fraction of studies with significant results in the expected direction: depreciation (appreciation) of domestic currency after purchases (sales) of foreign currency. 


\section{Appendix B Purchases vs Sales of Foreign Currency}

Table B1: FX Level in Response to a $\$ 1$ Billion USD Purchase

\begin{tabular}{|c|c|c|c|c|c|}
\hline USD Purchases & Obs & Sample Mean & $\overline{\mathrm{SD}}$ & $\mathrm{FE}$ & $\mathrm{RE}$ \\
\hline Total & 119 & $0.00924^{* *}$ & 0.00408 & $0.00003^{* * *}$ & $0.00030^{* * *}$ \\
\hline \multicolumn{6}{|c|}{ Relating to the Monetary Trilemma } \\
\hline \multicolumn{6}{|l|}{ By Trilemma Measures } \\
\hline Financial Openness $>0.5$ & 79 & 0.00414 & 0.00507 & $0.00003^{* * *}$ & $0.00032 * * *$ \\
\hline Financial Openness $<0.5$ & 39 & $0.01915^{* * *}$ & 0.00682 & 0.00002 & $0.00059^{*}$ \\
\hline Monetary Independence + Financial Openness $>0.5$ & 66 & 0.00023 & 0.00286 & $0.00002^{* * *}$ & $0.00032 * * *$ \\
\hline Monetary Independence + Financial Openness $<0.5$ & 52 & $0.02035 * *$ & 0.00838 & 0.00006 & $0.00047 * *$ \\
\hline Departure from CIP > mean & 14 & $0.01465^{*}$ & 0.00685 & $0.00067^{*}$ & $0.00207^{* *}$ \\
\hline Departure from CIP $<$ mean & 86 & $0.01157 * *$ & 0.00517 & $0.00004^{* * *}$ & $0.00033^{* * *}$ \\
\hline \multicolumn{6}{|l|}{ By Exchange Regime } \\
\hline Currency Board & 2 & -0.00488 & 0.00322 & $-0.00194 * * *$ & -0.00445 \\
\hline Pre-Announced Crawling Peg & 8 & 0.01725 & 0.00982 & 0.00029 & $0.00688^{* *} *$ \\
\hline Crawling Band & 41 & $0.02375^{* *}$ & 0.01099 & -0.00000 & $0.00065^{* *}$ \\
\hline Free Floating & 57 & -0.00172 & 0.00153 & $0.00004^{* * *}$ & $0.00034^{* * *}$ \\
\hline Freely Falling & 11 & 0.00874 & 0.00718 & 0.00002 & 0.00010 \\
\hline \multicolumn{6}{|l|}{ By Capital Controls } \\
\hline Restrictions on Inflows $>0.5$ & 33 & $0.03069 * *$ & 0.01263 & -0.00000 & 0.00035 \\
\hline Restrictions on Inflows $<0.5$ & 77 & 0.00223 & 0.00256 & $0.00004^{* * *}$ & $0.00036^{* * *}$ \\
\hline Restrictions on Outflows $>0.5$ & 37 & $0.02651 * *$ & 0.01124 & $0.00021^{* *}$ & $0.00116^{* *}$ \\
\hline Restrictions on Outflows $<0.5$ & 73 & 0.00279 & 0.00287 & $0.00002 * * *$ & $0.00030 * * *$ \\
\hline Overall Restrictions $>0.5$ & 34 & $0.02986 * *$ & 0.01228 & -0.00000 & $0.00047^{*}$ \\
\hline Overall Restrictions $<0.5$ & 76 & 0.00223 & 0.00259 & $0.00004^{* * *}$ & $0.00034^{* * *}$ \\
\hline \multicolumn{6}{|c|}{ Relating to the way FXI are conducted } \\
\hline \multicolumn{6}{|l|}{ By FX Mechanism } \\
\hline Auctions (Colombia) & 6 & $0.12759^{*}$ & 0.05408 & $0.00637 * *$ & $0.04464^{* *}$ \\
\hline Auctions (Mexico) & 3 & 0.00074 & 0.00038 & -0.00000 & -0.00000 \\
\hline Auctions (Turkey) & 8 & 0.01024 & 0.00997 & 0.00001 & 0.00004 \\
\hline Spot & 100 & 0.00243 & 0.00227 & $0.00004^{* * *}$ & $0.00034^{* * *}$ \\
\hline \multicolumn{6}{|l|}{ By Announcement } \\
\hline Secret (Dirty) & 8 & 0.01111 & 0.00975 & -0.00006 & -0.00013 \\
\hline Others & 110 & $0.00916 * *$ & 0.00436 & $0.00003^{* * *}$ & $0.00033^{* * *}$ \\
\hline \multicolumn{6}{|l|}{ By Intended Central Bank Objective } \\
\hline Influence FX Level & 72 & 0.00057 & 0.00132 & $0.00002^{* * *}$ & $0.00032 * * *$ \\
\hline Influence Volatility & 28 & $0.03240^{*}$ & 0.01591 & 0.00000 & 0.00047 \\
\hline Influence Level \& Volatility & 5 & 0.0023 & 0.00594 & -0.00015 & -0.00033 \\
\hline Asymmetry (Sales over Total in $1^{\text {st }}$ quartile) & 15 & 0.00307 & 0.00345 & $0.00042^{* * *}$ & 0.00023 \\
\hline Symmetry (Sales over Total in $2^{\text {nd }}$ or $3^{r d}$ quartile) & 25 & 0.00965 & 0.00585 & -0.00000 & $0.00030^{* *}$ \\
\hline Asymmetry (Sales over Total in $4^{t h}$ quartile) & 8 & -0.00133 & 0.00724 & 0.00109 & 0.00111 \\
\hline \multicolumn{6}{|l|}{ By Size of Intervention } \\
\hline Intervention Size in $1^{s t}$ quartile & 14 & 0.00036 & 0.00539 & $-0.00026 * * *$ & $-0.00317 * * *$ \\
\hline Intervention Size in $2^{n d}$ quartile & 18 & 0.02347 & 0.01947 & $0.00002^{* * *}$ & $0.00033^{* * *}$ \\
\hline Intervention Size in $3^{r d}$ quartile & 10 & -0.00021 & 0.00358 & 0.00000 & $0.00039^{* *}$ \\
\hline Intervention Size in $4^{t h}$ quartile & 12 & $0.04041^{*}$ & 0.01918 & 0.00008 & 0.00269 \\
\hline
\end{tabular}

Authors' calculations. Sample means are computed by regressing effect sizes on each variable from the first column (SD is the standard deviation). FE and RE denote Fixed and Random Effects in the standard metaanalysis context. Trilemma measures are obtained from Aizenman et al. (2008), exchange rate regimes are obtained from Ilzetzki et al. (2019), and capital controls are obtained from Fernández et al. (2016). All other variables were obtained from Bloomberg, directly from each study, and from official central banks' websites (see Section 2.1). ${ }^{* * *},{ }^{* *}$, and ${ }^{*}$ denote statistical significance at the 1,5 , and 10 percent level respectively. 
Table B2: Other Effects: FX Level in Response to a \$1 Billion USD Purchase

\begin{tabular}{|c|c|c|c|c|c|}
\hline USD Purchases & Obs & Sample Mean & SD & $\overline{\mathrm{FE}}$ & $\mathrm{RE}$ \\
\hline Total & 119 & $0.00924^{* *}$ & 0.00408 & $0.00003^{* * *}$ & $0.00030^{* * *}$ \\
\hline \multicolumn{6}{|c|}{ Relating to Macroeconomic Variables } \\
\hline \multicolumn{6}{|l|}{ By GDP Classification } \\
\hline Low Income & 4 & -0.02508 & 0.02521 & -0.00231 & -0.00055 \\
\hline Lower Middle Income & 13 & 0.01522 & 0.00872 & -0.00001 & 0.00181 \\
\hline Upper Middle Income & 42 & $0.02484^{* *}$ & 0.01002 & -0.00000 & $0.00051 * *$ \\
\hline High Income & 60 & -0.00069 & 0.00235 & $0.00004 * * *$ & $0.00031^{* * *}$ \\
\hline \multicolumn{6}{|l|}{ By Financial Crisis } \\
\hline Systemic Banking Crisis $>10 \%$ of analyzed period & 12 & -0.00234 & 0.00332 & $0.00040 * * *$ & $0.00049^{* * *}$ \\
\hline Systemic Banking Crisis $<10 \%$ of analyzed period & 21 & 0.0024 & 0.00188 & $0.00003^{* * *}$ & $0.00032^{* * *}$ \\
\hline Systemic Banking Crisis Intensity $>$ mean & 30 & 0.00054 & 0.00187 & $0.00003^{* * *}$ & $0.00043^{* * *}$ \\
\hline Systemic Banking Crisis Intensity $<$ mean & 3 & 0.00204 & 0.00332 & $-0.00146 * * *$ & 0.00081 \\
\hline Currency Crisis $>25 \%$ of analyzed period & 8 & -0.00433 & 0.00426 & 0.00002 & 0.00003 \\
\hline Currency Crisis $<25 \%$ of analyzed period & 2 & 0.00389 & 0.00477 & 0.00193 & 0.00345 \\
\hline \multicolumn{6}{|l|}{ By Financial Deepening } \\
\hline Financial Deepening $>$ mean & 49 & 0.00185 & 0.00141 & $0.00004^{* * *}$ & $0.00035^{* * *}$ \\
\hline Financial Deepening $<$ mean & 58 & $0.01770^{* *}$ & 0.00790 & -0.00000 & $0.00027^{*}$ \\
\hline \multicolumn{6}{|l|}{ By Exchange Rate Volatility } \\
\hline Exchange Volatility $>$ mean & 44 & 0.00522 & 0.00869 & $0.00002^{* * *}$ & $0.00022 *$ \\
\hline Exchange Volatility $<$ mean & 75 & $0.01160^{* * *}$ & 0.00401 & $0.00003^{* * *}$ & $0.00041 * * *$ \\
\hline \multicolumn{6}{|l|}{ By International Reserves } \\
\hline FX Reserves > mean & 40 & 0.00317 & 0.00354 & $0.00003^{* * *}$ & $0.00044^{* * *}$ \\
\hline FX Reserves < mean & 71 & $0.01535 * *$ & 0.00638 & $0.00002 * * *$ & $0.00028^{* * *}$ \\
\hline \multicolumn{6}{|l|}{ By Sovereign Debt (in foreign currency) } \\
\hline External Debt > mean & 18 & -0.00074 & 0.00741 & 0.00002 & 0.00011 \\
\hline External Debt $<$ mean & 36 & $0.03055^{* *}$ & 0.01169 & -0.00000 & $0.00049^{*}$ \\
\hline \multicolumn{6}{|l|}{ By Country's Credit Rating } \\
\hline Moody's > mean & 57 & 0.00228 & 0.00225 & $0.00004 * * *$ & $0.00036^{* * *}$ \\
\hline Moody's < mean & 52 & $0.02075^{* *}$ & 0.00869 & -0.00000 & $0.00023^{*}$ \\
\hline $\mathrm{S} \& \mathrm{P}>$ mean & 57 & 0.00228 & 0.00225 & $0.00004^{* * *}$ & $0.00036^{* * *}$ \\
\hline $\mathrm{S} \& \mathrm{P}<$ mean & 52 & $0.02075^{* *}$ & 0.00869 & -0.00000 & $0.00023^{*}$ \\
\hline Fitch $>$ mean & 57 & 0.00228 & 0.00225 & $0.00004 * * *$ & $0.00036 * * *$ \\
\hline Fitch $<$ mean & 52 & $0.02075^{* *}$ & 0.00869 & -0.00000 & $0.00023^{*}$ \\
\hline \multicolumn{6}{|c|}{ Relating to each Study } \\
\hline \multicolumn{6}{|l|}{ By Treatment Variable } \\
\hline Dummy & 15 & 0.00208 & 0.00435 & $0.00073^{* * *}$ & $0.00067 * * *$ \\
\hline No Dummy & 104 & $0.01027^{* *}$ & 0.00462 & $0.00002^{* * *}$ & $0.00022 * * *$ \\
\hline \multicolumn{6}{|l|}{ By Publication Type } \\
\hline Web of Science - ISI & 59 & 0.00321 & 0.00360 & $0.00003^{* * *}$ & $0.00031 * * *$ \\
\hline Working Paper or Other & 51 & $0.01578^{*}$ & 0.00837 & 0.00001 & $0.00028^{* *}$ \\
\hline Impact Factor $>$ mean & 32 & 0.00593 & 0.00536 & $0.00002 * * *$ & $0.00032 *$ \\
\hline Impact Factor $<$ mean & 27 & -0.00003 & 0.00467 & $0.00053^{* * *}$ & $0.00029^{*}$ \\
\hline Citations $>$ mean & 26 & 0.01192 & 0.01477 & -0.00000 & -0.00011 \\
\hline Citations $<$ mean & 93 & $0.00849^{* *}$ & 0.00327 & $0.00004 * * *$ & $0.00039 * * *$ \\
\hline \multicolumn{6}{|l|}{ By Methodology } \\
\hline Event Study & 4 & 0.01988 & 0.01156 & 0.00068 & 0.00125 \\
\hline GARCH & 86 & 0.00505 & 0.00474 & $0.00003 * * *$ & $0.00026^{* * *}$ \\
\hline IV \& 2SLS & 2 & $0.00702 * *$ & 0.00031 & $0.00695^{* * *}$ & $0.00695^{* * *}$ \\
\hline OLS & 14 & 0.01146 & 0.00764 & $0.00002^{* * *}$ & $0.00057^{* * *}$ \\
\hline PSM & 3 & 0.0021 & 0.00154 & $0.00054^{* *}$ & 0.00062 \\
\hline RDD & 2 & 0.15833 & 0.06389 & $0.12182^{* * *}$ & $0.12987^{* * *}$ \\
\hline VAR VEC SUR & 4 & 0.01234 & 0.00966 & $0.00030 * * *$ & -0.00054 \\
\hline
\end{tabular}

Authors' calculations. Sample means are computed by regressing effect sizes on each variable from the first column (SD is the standard deviation). FE and RE denote Fixed and Random Effects in the standard meta-analysis context. Financial crises are obtained from Laeven and Valencia (2020). All other variables were obtained from Bloomberg, directly from each study, and from official central banks' websites (see Section 2.1). ${ }^{* *},{ }^{* *}$, and ${ }^{*}$ denote statistical significance at the 1,5 , and 10 percent level respectively. 
Table B3: FX Level in Response to a $\$ 1$ Billion USD Sale

\begin{tabular}{|c|c|c|c|c|c|}
\hline USD Purchases & $\overline{\mathrm{O} \text { Obs }}$ & Sample Mean & $\overline{\mathrm{SD}}$ & $\overline{\mathrm{FE}}$ & $\overline{\mathrm{RE}}$ \\
\hline Total & 39 & -0.01031 & 0.00752 & $-0.00132^{* * *}$ & $-0.00490^{* * *}$ \\
\hline \multicolumn{6}{|c|}{ Relating to the Monetary Trilemma } \\
\hline \multicolumn{6}{|l|}{ By Trilemma Measures } \\
\hline Financial Openness $>0.5$ & 17 & -0.01138 & 0.00677 & $-0.00195 * * *$ & $-0.00228^{* * *}$ \\
\hline Financial Openness $<0.5$ & 21 & -0.00905 & 0.01302 & $-0.00113 * * *$ & $-0.00749 * * *$ \\
\hline Monetary Independence + Financial Openness $>0.5$ & 8 & -0.01485 & 0.01199 & $-0.00475 * * *$ & -0.00383 \\
\hline Monetary Independence + Financial Openness $<0.5$ & 30 & -0.00883 & 0.00931 & $-0.00118 * * *$ & $-0.00504^{* * *}$ \\
\hline Departure from CIP > mean & 8 & -0.01173 & 0.00694 & $-0.00132 * * *$ & -0.00107 \\
\hline Departure from CIP $<$ mean & 14 & -0.01713 & 0.01240 & $-0.00044^{*}$ & $-0.00258^{*}$ \\
\hline \multicolumn{6}{|l|}{ By Exchange Regime } \\
\hline Pre-Announced Crawling Peg & 3 & -0.00558 & 0.00349 & $-0.00676^{* * *}$ & $-0.00676^{* * *}$ \\
\hline Crawling Band & 14 & $-0.03189^{* *}$ & 0.01411 & $-0.00985^{* * *}$ & $-0.02328^{* * *}$ \\
\hline Free Floating & 10 & -0.00143 & 0.00114 & $-0.00178 * * *$ & -0.00137 \\
\hline Freely Falling & 11 & 0.00701 & 0.01824 & $-0.00100 * * *$ & $-0.00822^{* * *}$ \\
\hline \multicolumn{6}{|l|}{ By Capital Controls } \\
\hline Restrictions on Inflows $>0.5$ & 15 & $-0.03102^{* *}$ & 0.01213 & $-0.00170^{* * *}$ & $-0.00461^{* * *}$ \\
\hline Restrictions on Inflows $<0.5$ & 22 & 0.00057 & 0.00929 & $-0.00126 * * *$ & $-0.00557^{* * *}$ \\
\hline Restrictions on Outflows $>0.5$ & 14 & -0.02035 & 0.01259 & $-0.00191 * * *$ & $-0.00609 * * *$ \\
\hline Restrictions on Outflows $<0.5$ & 23 & -0.0073 & 0.00988 & $-0.00124^{* * *}$ & $-0.00498 * * *$ \\
\hline Overall Restrictions $>0.5$ & 15 & $-0.03102^{* *}$ & 0.01213 & $-0.00170 * * *$ & $-0.00461 * * *$ \\
\hline Overall Restrictions $<0.5$ & 22 & 0.00057 & 0.00929 & $-0.00126 * * *$ & $-0.00557^{* * *}$ \\
\hline \multicolumn{6}{|c|}{ Relating to the way FXI are conducted } \\
\hline \multicolumn{6}{|l|}{ By FX Mechanism } \\
\hline Auctions (Colombia) & 2 & -0.10011 & 0.07211 & $-0.03762^{* * *}$ & -0.09359 \\
\hline Auctions (Turkey) & 6 & $-0.01286^{*}$ & 0.00630 & 0.00032 & 0.00026 \\
\hline Forwards & 2 & -0.00019 & 0.00119 & $-0.00126 * * *$ & -0.00084 \\
\hline Spot & 27 & -0.00138 & 0.00819 & $-0.00551 * * *$ & $-0.00783^{* * *}$ \\
\hline \multicolumn{6}{|l|}{ By Announcement } \\
\hline Announced & 3 & -0.00562 & 0.00260 & $-0.00153 * * *$ & $-0.00371^{*}$ \\
\hline Others & 35 & -0.011 & 0.00838 & $-0.00128 * * *$ & $-0.00535^{* * *}$ \\
\hline \multicolumn{6}{|l|}{ By Intended Central Bank Objective } \\
\hline Influence FX Level & 21 & $-0.01605^{* * *}$ & 0.00545 & $-0.00060 * *$ & $-0.00434^{* *}$ \\
\hline Influence Volatility & 14 & -0.00461 & 0.01957 & $-0.00199 * * *$ & $-0.01061^{* * *}$ \\
\hline Influence Level \& Volatility & 3 & 0.00033 & 0.00176 & -0.00070 & 0.00008 \\
\hline Asymmetry (Sales over Total in $1^{s t}$ quartile) & 5 & 0.03118 & 0.03798 & -0.00111 & -0.00226 \\
\hline Symmetry (Sales over Total in $2^{\text {nd }}$ or $3^{r d}$ quartile) & 10 & $-0.03407^{*}$ & 0.01770 & -0.00000 & $-0.00239^{* *}$ \\
\hline Asymmetry (Sales over Total in $4^{t h}$ quartile) & 6 & $-0.01316^{*}$ & 0.00542 & $-0.01209 * * *$ & $-0.01334 * * *$ \\
\hline \multicolumn{6}{|l|}{ By Size of Intervention } \\
\hline Intervention Size in $1^{\text {st }}$ quartile & 5 & $-0.01055^{*}$ & 0.00475 & $-0.00544 * * *$ & $-0.00544^{* * *}$ \\
\hline Intervention Size in $3^{r d}$ quartile & 6 & -0.02082 & 0.01743 & -0.00002 & -0.00829 \\
\hline Intervention Size in $4^{t h}$ quartile & 6 & -0.03901 & 0.02728 & $0.00086^{*}$ & -0.00333 \\
\hline
\end{tabular}

Authors' calculations. Sample means are computed by regressing effect sizes on each variable from the first column (SD is the standard deviation). FE and RE denote Fixed and Random Effects in the standard metaanalysis context. Trilemma measures are obtained from Aizenman et al. (2008), exchange rate regimes are obtained from Ilzetzki et al. (2019), and capital controls are obtained from Fernández et al. (2016). All other variables were obtained from Bloomberg, directly from each study, and from official central banks' websites (see Section 2.1). ${ }^{* * *},{ }^{* *}$, and ${ }^{*}$ denote statistical significance at the 1,5 , and 10 percent level respectively. 
Table B4: Other Effects: FX Level in Response to a $\$ 1$ Billion USD Sale

\begin{tabular}{|c|c|c|c|c|c|}
\hline USD Purchases & Obs & Sample Mean & SD & FE & $\mathrm{RE}$ \\
\hline Total & 39 & -0.01031 & 0.00752 & $-0.00132^{* * *}$ & $-0.00490^{* * *}$ \\
\hline \multicolumn{6}{|c|}{ Relating to Macroeconomic Variables } \\
\hline \multicolumn{6}{|l|}{ By GDP Classification } \\
\hline Low Income & 4 & -0.00223 & 0.01881 & $-0.01339 * * *$ & $-0.01545^{* * *}$ \\
\hline Lower Middle Income & 8 & 0.01855 & 0.02403 & $-0.00039^{*}$ & -0.00089 \\
\hline Upper Middle Income & 22 & $-0.02345 * *$ & 0.00884 & -0.00025 & $-0.00263^{* *}$ \\
\hline High Income & 5 & -0.00511 & 0.00362 & $-0.00467 * * *$ & -0.00324 \\
\hline \multicolumn{6}{|l|}{ By Financial Crisis } \\
\hline Systemic Banking Crisis $<10 \%$ of analyzed period & 3 & -0.01677 & 0.00998 & $-0.00585 * * *$ & $-0.01486 * * *$ \\
\hline Systemic Banking Crisis Intensity $<$ mean & 3 & -0.01677 & 0.00998 & $-0.00585 * * *$ & $-0.01486 * * *$ \\
\hline Currency Crisis $>25 \%$ of analyzed period & 6 & 0.02152 & 0.03258 & 0.00032 & 0.00031 \\
\hline Currency Crisis $<25 \%$ of analyzed period & 3 & -0.00901 & 0.01667 & $-0.01340 * * *$ & -0.01401 \\
\hline \multicolumn{6}{|l|}{ By Financial Deepening } \\
\hline Financial Deepening $>$ mean & 4 & -0.00616 & 0.00447 & $-0.00469 * * *$ & -0.00331 \\
\hline Financial Deepening $<$ mean & 34 & -0.01107 & 0.00862 & $-0.00119 * * *$ & $-0.00525 * * *$ \\
\hline \multicolumn{6}{|l|}{ By Exchange Rate Volatility } \\
\hline Exchange Volatility $>$ mean & 21 & 0.00305 & 0.00941 & $-0.00031^{* *}$ & $-0.00157 * *$ \\
\hline Exchange Volatility $<$ mean & 18 & $-0.02589 * *$ & 0.01121 & $-0.00573^{* * *}$ & $-0.01404 * * *$ \\
\hline \multicolumn{6}{|l|}{ By International Reserves } \\
\hline FX Reserves > mean & 14 & $-0.00901 *$ & 0.00493 & $-0.00161 * * *$ & $-0.00231 * * *$ \\
\hline FX Reserves < mean & 24 & -0.01145 & 0.01198 & $-0.00127^{* * *}$ & $-0.00662^{* * *}$ \\
\hline \multicolumn{6}{|l|}{ By Sovereign Debt (in foreign currency) } \\
\hline External Debt > mean & 15 & 0.00754 & 0.01365 & $-0.00102 * * *$ & $-0.00657 * * *$ \\
\hline External Debt $<$ mean & 12 & $-0.03217^{*}$ & 0.01506 & $-0.00146^{* * *}$ & -0.00167 \\
\hline \multicolumn{6}{|l|}{ By Country's Credit Rating } \\
\hline Moody's > mean & 4 & -0.00616 & 0.00447 & $-0.00469 * * *$ & -0.00331 \\
\hline Moody's < mean & 30 & -0.01337 & 0.00944 & $-0.00034^{* *}$ & $-0.00184^{* *}$ \\
\hline $\mathrm{S} \& \mathrm{P}>$ mean & 11 & $-0.01165^{*}$ & 0.00608 & $-0.00509 * * *$ & $-0.00607 * * *$ \\
\hline $\mathrm{S} \& \mathrm{P}<$ mean & 24 & -0.0115 & 0.01166 & $-0.00029^{* *}$ & $-0.00119^{* *}$ \\
\hline Fitch $>$ mean & 11 & $-0.01165^{*}$ & 0.00608 & $-0.00509 * * *$ & $-0.00607 * * *$ \\
\hline Fitch $<$ mean & 24 & -0.00884 & 0.01195 & -0.00028 & -0.00095 \\
\hline \multicolumn{6}{|c|}{ Relating to each Study } \\
\hline \multicolumn{6}{|l|}{ By Treatment Variable } \\
\hline Dummy & 8 & 0.01602 & 0.02390 & $-0.00159 * * *$ & $-0.00202 * * *$ \\
\hline No Dummy & 31 & $-0.01710^{* *}$ & 0.00694 & $-0.00122 * * *$ & $-0.00597 * * *$ \\
\hline \multicolumn{6}{|l|}{ By Publication Type } \\
\hline Web of Science - ISI & 8 & -0.02544 & 0.02120 & 0.00009 & -0.00274 \\
\hline Working Paper or Other & 29 & -0.00546 & 0.00829 & $-0.00181 * * *$ & $-0.00546 * * *$ \\
\hline Impact Factor $>$ mean & 2 & -0.08656 & 0.08566 & -0.01551 & -0.08120 \\
\hline Impact Factor $<$ mean & 6 & -0.00507 & 0.00419 & 0.00009 & -0.00216 \\
\hline Citations > mean & 12 & $-0.02146 * *$ & 0.00871 & -0.00015 & $-0.01268^{* *}$ \\
\hline Citations $<$ mean & 27 & -0.00535 & 0.01010 & $-0.00199 * * *$ & $-0.00448^{* * *}$ \\
\hline \multicolumn{6}{|l|}{ By Methodology } \\
\hline Event Study & 2 & -0.02317 & 0.00483 & $-0.02283^{* * *}$ & $-0.02283^{* * *}$ \\
\hline GARCH & 21 & -0.00225 & 0.01103 & $-0.00127 * * *$ & $-0.00537 * * *$ \\
\hline IV \& 2 SLS & 7 & -0.01478 & 0.00931 & $-0.00796^{* * *}$ & $-0.01417^{* * *}$ \\
\hline OLS & 6 & -0.00423 & 0.00424 & $-0.00129 * * *$ & -0.00078 \\
\hline PSM & 2 & -0.00362 & 0.00407 & -0.00354 & -0.00357 \\
\hline
\end{tabular}

Authors' calculations. Sample means are computed by regressing effect sizes on each variable from the first column (SD is the standard deviation). FE and RE denote Fixed and Random Effects in the standard meta-analysis context. Financial crises are obtained from Laeven and Valencia (2020). All other variables were obtained from Bloomberg, directly from each study, and from official central banks' websites (see Section 2.1). ${ }^{* * *},{ }^{* *}$, and ${ }^{*}$ denote statistical significance at the 1,5 , and 10 percent level respectively. 


\section{Appendix C Synthetic Effect Sizes}

Table C5: FX Level in Response to a $\$ 1$ Billion Net USD Purchase (with synthetic effect sizes)

\begin{tabular}{|c|c|c|c|c|c|}
\hline USD Purchases & Obs & Sample Mean & SD & FE & $\mathrm{RE}$ \\
\hline Total & 68 & $0.00871^{*}$ & 0.00502 & $0.00022^{* * *}$ & $0.00044^{* * *}$ \\
\hline \multicolumn{6}{|c|}{ Relating to the Monetary Trilemma } \\
\hline \multicolumn{6}{|l|}{ By Trilemma Measures } \\
\hline Financial Openness $>0.5$ & 44 & 0.00797 & 0.00878 & $0.00023^{* *}$ & $0.00035^{*}$ \\
\hline Financial Openness $<0.5$ & 30 & $0.01993^{*}$ & 0.00981 & -0.00003 & $0.00189^{* *}$ \\
\hline Financial Openness + Monetary Independence $>0.5$ & 35 & 0.00077 & 0.00446 & $0.00022 * * *$ & $0.00041^{* * *}$ \\
\hline Financial Openness + Monetary Independence $<0.5$ & 36 & $0.01606^{*}$ & 0.00835 & 0.00013 & $0.00125^{*}$ \\
\hline Departure from CIP $>$ mean & 10 & $0.01467^{* *}$ & 0.0063 & 0.00027 & 0.00139 \\
\hline Departure from CIP $<$ mean & 50 & $0.01133^{*}$ & 0.00568 & $0.00021 * * *$ & 0.00028 \\
\hline \multicolumn{6}{|l|}{ By Exchange Regime } \\
\hline Currency Board & 2 & -0.00407 & 0.00403 & -0.00036 & -0.00373 \\
\hline Pre-Announced Crawling Peg & 6 & 0.02056 & 0.01253 & $0.00224^{* *}$ & $0.0085^{* *}$ \\
\hline Crawling Band & 24 & $0.02245^{*}$ & 0.01245 & $0.00041 * *$ & 0.00189 \\
\hline Free Floating & 31 & -0.00053 & 0.00206 & $0.00022 * * *$ & $0.00042^{* * *}$ \\
\hline Freely Falling & 10 & -0.0007 & 0.0118 & -0.00011 & 0.00048 \\
\hline \multicolumn{6}{|l|}{ By Capital Controls ${ }^{(b)}$} \\
\hline Restrictions on Inflows $>0.5$ & 23 & $0.03299^{* * *}$ & 0.01082 & $0.00034^{* *}$ & $0.00267^{* *}$ \\
\hline Restrictions on Inflows $<0.5$ & 49 & -0.00054 & 0.00384 & $0.00021^{* * *}$ & $0.00044^{* * *}$ \\
\hline Restrictions on Outflows $>0.5$ & 22 & $0.02785^{* *}$ & 0.01133 & $0.00043^{* *}$ & $0.00254^{* *}$ \\
\hline Restrictions on Outflows $<0.5$ & 45 & 0.00186 & 0.00452 & $0.00021^{* * *}$ & $0.00034^{*}$ \\
\hline Overall Restrictions $>0.5$ & 24 & $0.03171^{* * *}$ & 0.01044 & $0.00041^{* *}$ & $0.00244^{* *}$ \\
\hline Overall Restrictions $<0.5$ & 48 & -0.0006 & 0.00392 & $0.00021^{* * *}$ & $0.0004^{* * *}$ \\
\hline \multicolumn{6}{|c|}{ Relating to the way FXI are conducted } \\
\hline \multicolumn{6}{|l|}{ By FX Mechanism } \\
\hline Auctions (Brazil) & 2 & 0.00185 & 0.00485 & -0.00022 & 0.00153 \\
\hline Auctions (Colombia) & 5 & $0.15570^{*}$ & 0.0597 & $0.04385^{* * *}$ & $0.05904^{* * *}$ \\
\hline Auctions (Mexico) & 3 & 0.01574 & 0.01463 & $0.04175 * *$ & $0.04175^{* *}$ \\
\hline Auctions (Turkey) & 7 & 0.01526 & 0.0087 & -0.00014 & -0.00016 \\
\hline Forwards & 2 & 0.0001 & 0.0001 & 0.00019 & 0.00019 \\
\hline \multirow{2}{*}{\multicolumn{6}{|c|}{ By Announcement }} \\
\hline & & & & & \\
\hline Announced & 3 & 0.00401 & 0.00177 & $0.00156^{* * *}$ & $0.00246 * * *$ \\
\hline Secret (Dirty) & 6 & 0.01258 & 0.01084 & 0.00001 & -0.00015 \\
\hline Others & 65 & 0.00832 & 0.00519 & $0.00002 * * *$ & $0.00042 * * *$ \\
\hline \multicolumn{6}{|l|}{ By Intended Central Bank Objective } \\
\hline Influence FX Level & 46 & 0.00318 & 0.0022 & $0.00022 * * *$ & $0.00042^{* * *}$ \\
\hline Influence Volatility & 23 & 0.02112 & 0.01421 & 0.00005 & $0.00760 * *$ \\
\hline Influence Level \& Volatility & 5 & 0.00213 & 0.00596 & -0.00073 & -0.00044 \\
\hline Asymmetry (Sales over Total in $1^{s t}$ quartile) & 6 & -0.01185 & 0.01594 & $0.00032 * * *$ & -0.00009 \\
\hline Symmetry (Sales over Total in $2^{n d}$ or $3^{r d}$ quartile) & 17 & $0.01822 *$ & 0.00984 & $0.00023^{* *}$ & 0.00087 \\
\hline Asymmetry (Sales over Total in $4^{t h}$ quartile) & 6 & 0.00436 & 0.00646 & $0.00515^{* * *}$ & $0.00617^{*}$ \\
\hline \multicolumn{6}{|l|}{ By Size of Intervention } \\
\hline Intervention Size in $11^{\text {st }}$ quartile & 12 & -0.00119 & 0.00485 & -0.00014 & -0.00140 \\
\hline Intervention Size in $2^{\text {nd }}$ quartile & 16 & -0.00408 & 0.01249 & $0.00002^{* * *}$ & $0.00029^{* * *}$ \\
\hline Intervention Size in $3^{r d}$ quartile & 9 & $0.00956^{*}$ & 0.00443 & $0.00037^{* * *}$ & $0.00043^{* * *}$ \\
\hline Intervention Size in $4^{t h}$ quartile & 13 & $0.04139 * *$ & 0.01861 & $-0.00040^{* *}$ & 0.00436 \\
\hline
\end{tabular}

Authors' calculations. Sample means are computed by regressing effect sizes on each variable from the first column (SD is the standard deviation). FE and RE denote Fixed and Random Effects in the standard meta-analysis context. Trilemma measures are obtained from Aizenman et al. (2008), exchange rate regimes are obtained from Ilzetzki et al. (2019), and capital controls are obtained from Fernández et al. (2016). All other variables were obtained from Bloomberg, directly from each study, and from official central banks' websites (see Section 2.1). ***, **, and $*$ denote statistical significance at the 1,5 , and 10 percent level respectively. 
Table C6: Other Effects: FX Level in Response to a $\$ 1$ Billion Net USD Purchase (with synthetic effect sizes)

\begin{tabular}{|c|c|c|c|c|c|}
\hline USD Purchases & Obs & Sample Mean & SD & FE & $\mathrm{RE}$ \\
\hline Total & 68 & $0.00871^{*}$ & 0.00502 & $0.00022^{* * *}$ & $0.00044^{* * *}$ \\
\hline \multicolumn{6}{|c|}{ Relating to Macroeconomic Variables } \\
\hline \multicolumn{6}{|l|}{ By GDP Classification } \\
\hline Low Income & 5 & -0.02675 & 0.02181 & 0.00175 & 0.00141 \\
\hline Lower Middle Income & 11 & 0.00708 & 0.01345 & 0.00001 & 0.00048 \\
\hline Upper Middle Income & 25 & $0.02931 * * *$ & 0.01005 & 0.00013 & $0.00125 *$ \\
\hline High Income & 31 & -0.00151 & 0.00250 & $0.00022^{* * *}$ & $0.00037^{*}$ \\
\hline \multicolumn{6}{|l|}{ By Financial Crisis } \\
\hline Systemic Banking Crisis $>10 \%$ of analyzed period & 9 & -0.0037 & 0.00436 & $0.00040^{* * *}$ & $0.00043^{* * *}$ \\
\hline Systemic Banking Crisis $<10 \%$ of analyzed period & 13 & 0.00416 & 0.00309 & $0.00018^{* * *}$ & $0.00042^{*}$ \\
\hline Systemic Banking Crisis Intensity $>$ mean & 20 & 0.00034 & 0.00281 & $0.00023^{* * *}$ & $0.00037^{* * *}$ \\
\hline Systemic Banking Crisis Intensity $<$ mean & 2 & 0.00705 & 0.00708 & 0.00032 & 0.00672 \\
\hline Currency Crisis $>25 \%$ of analyzed period & 7 & -0.01145 & 0.01354 & -0.00014 & -0.00014 \\
\hline Currency Crisis $<25 \%$ of analyzed period & 2 & -0.00379 & 0.01791 & $0.01280^{* * *}$ & -0.00050 \\
\hline \multicolumn{6}{|l|}{ By Financial Deepening } \\
\hline Financial Deepening $>$ mean & 26 & 0.00231 & 0.00232 & $0.00022^{* * *}$ & $0.00035^{*}$ \\
\hline Financial Deepening $<$ mean & 40 & $0.01411^{*}$ & 0.00830 & 0.00014 & 0.00112 \\
\hline \multicolumn{6}{|l|}{ By Exchange Rate Volatility } \\
\hline Echange Volatility $>$ mean & 30 & 0.00798 & 0.01293 & 0.00007 & 0.00030 \\
\hline Exchange Volatility $<$ mean & 51 & $0.01424^{* *}$ & 0.00588 & $0.00039 * * *$ & $0.00057 * * *$ \\
\hline \multicolumn{6}{|l|}{ By International Reserves } \\
\hline FX Reserves > mean & 27 & 0.00351 & 0.00520 & $0.00021^{* * *}$ & $0.00054^{* * *}$ \\
\hline FX Reserves $<$ mean & 44 & $0.01223^{*}$ & 0.00703 & $0.00038^{* * *}$ & 0.00054 \\
\hline \multicolumn{6}{|l|}{ By Sovereign Debt (in foreign currency) } \\
\hline External Debt $>$ mean & 17 & -0.00926 & 0.00943 & -0.00011 & 0.00059 \\
\hline External Debt $<$ mean & 23 & $0.03467^{* * *}$ & 0.01104 & $0.00040^{* *}$ & $0.00194 *$ \\
\hline \multicolumn{6}{|l|}{ By Country's Credit Rating } \\
\hline Moodys > mean & 31 & 0.00025 & 0.00243 & $0.00022^{* * *}$ & $0.00037^{*}$ \\
\hline Moodys $<$ mean & 33 & $0.02073^{* *}$ & 0.00955 & 0.00010 & 0.00085 \\
\hline $\mathrm{S} \& \mathrm{P}>$ mean & 32 & 0.00094 & 0.00245 & $0.00022^{* * *}$ & $0.00038^{*}$ \\
\hline $\mathrm{S} \& \mathrm{P}<$ mean & 33 & $0.01940^{*}$ & 0.00964 & 0.00010 & 0.00077 \\
\hline Fitch $>$ mean & 32 & 0.00094 & 0.00245 & $0.00022^{* * *}$ & $0.00038^{*}$ \\
\hline Fitch $<$ mean & 33 & $0.01747^{*}$ & 0.00987 & 0.00009 & 0.00051 \\
\hline \multicolumn{6}{|c|}{ Relating to each Study } \\
\hline \multicolumn{6}{|l|}{ By Treatment Variable } \\
\hline Dummy & 12 & -0.00726 & 0.00847 & $0.00076^{* * *}$ & $0.00083^{* * *}$ \\
\hline No Dummy & 59 & $0.01183^{* *}$ & 0.00545 & $0.00008^{* *}$ & $0.00039^{*}$ \\
\hline \multicolumn{6}{|l|}{ By Publication Type } \\
\hline Web of Science - ISI & 29 & 0.00218 & 0.00601 & $0.00017^{* * *}$ & $0.00037^{*}$ \\
\hline Working Paper or Other & 33 & 0.01224 & 0.00826 & $0.00041^{* * *}$ & $0.00097^{* * *}$ \\
\hline Impact Factor $>$ mean & 15 & 0.01059 & 0.01081 & -0.00002 & 0.00053 \\
\hline Impact Factor $<$ mean & 14 & -0.00379 & 0.00791 & $0.00051 * * *$ & 0.00004 \\
\hline Citations $>$ mean & 13 & 0.0062 & 0.00778 & $0.00061 * * *$ & -0.00477 \\
\hline Citations $<$ mean & 55 & 0.0093 & 0.00595 & $0.00021 * * *$ & $0.00048^{* * *}$ \\
\hline \multicolumn{6}{|l|}{ By Methodology } \\
\hline Event Study & 2 & $0.02128 * *$ & 0.00090 & $0.02079^{* * *}$ & $0.02079 * * *$ \\
\hline GARCH & 50 & 0.00166 & 0.00451 & $0.00046^{* * *}$ & $0.00045^{* * *}$ \\
\hline IV \& 2SLS & 2 & 0.01463 & 0.00761 & $0.00760^{* * *}$ & $0.00760 * * *$ \\
\hline OLS & 9 & 0.00559 & 0.00324 & 0.00008 & $0.00076^{* *}$ \\
\hline PSM & 2 & 0.002 & 0.00152 & $0.00050^{*}$ & $0.00050^{*}$ \\
\hline $\mathrm{RDD}$ & 2 & 0.17778 & 0.04444 & $0.15032^{* * *}$ & $0.15032^{* * *}$ \\
\hline VAR VEC SUR & 2 & 0.01234 & 0.01516 & $-0.00279^{* * *}$ & 0.00779 \\
\hline
\end{tabular}

Authors' calculations. Sample means are computed by regressing effect sizes on each variable from the first column (SD is the standard deviation). FE and RE denote Fixed and Random Effects in the standard meta-analysis context. Financial crises are obtained from Laeven and Valencia (2020). All other variables were obtained from Bloomberg, directly from each study, and from official central banks' websites (see Section 2.1$) .{ }^{* * *},{ }^{* *}$, and ${ }^{*}$ denote statistical significance at the 1,5 , and 10 percent level respectively. 


\section{Appendix D Studies using daily frequency data}

Table D7: FX Level in Response to a $\$ 1$ Billion Net USD Purchase (with daily frequency data)

\begin{tabular}{|c|c|c|c|c|c|}
\hline USD Purchases & Obs & Sample Mean & $\overline{\mathrm{SD}}$ & $\overline{\mathrm{FE}}$ & $\overline{\mathrm{RE}}$ \\
\hline Total & 138 & $0.01068^{* * *}$ & 0.00402 & $0.00003^{* * *}$ & $0.00039^{* * *}$ \\
\hline \multicolumn{6}{|c|}{ Relating to the Monetary Trilemma } \\
\hline \multicolumn{6}{|l|}{ By Trilemma Measures } \\
\hline Financial Openness $>0.5$ & 90 & 0.00643 & 0.00458 & $0.00003^{* * *}$ & $0.00043^{* * *}$ \\
\hline Financial Openness $<0.5$ & 46 & $0.01851^{* *}$ & 0.00803 & 0.00002 & $0.00070^{* *}$ \\
\hline Financial Openness + Monetary Independence $>0.5$ & 69 & 0.00305 & 0.00300 & $0.00003^{* * *}$ & $0.00042^{* * *}$ \\
\hline Financial Openness + Monetary Independence $<0.5$ & 67 & $0.01820 * *$ & 0.00761 & $0.00008^{*}$ & $0.00066^{* *}$ \\
\hline Departure from CIP > mean & 20 & $0.01220^{* *}$ & 0.00530 & $0.00100 * * *$ & $0.00137^{* * *}$ \\
\hline Departure from CIP $<$ mean & 89 & $0.01365^{* *}$ & 0.00531 & $0.00004^{* * *}$ & $0.00046^{* * *}$ \\
\hline \multicolumn{6}{|l|}{ By Exchange Regime } \\
\hline Pre-Announced Crawling Peg & 6 & 0.01712 & 0.01269 & 0.00031 & $0.00303^{*}$ \\
\hline Crawling Band & 52 & $0.02725^{* * *}$ & 0.00929 & -0.00000 & $0.00088^{* *}$ \\
\hline Free Floating & 63 & -0.00047 & 0.00127 & $0.00004^{* * *}$ & $0.00049^{* * *}$ \\
\hline Freely Falling & 17 & -0.00093 & 0.01238 & -0.00000 & -0.00007 \\
\hline \multicolumn{6}{|l|}{ By Capital Controls } \\
\hline Restrictions on Inflows $>0.5$ & 38 & $0.03630 * * *$ & 0.01167 & -0.00000 & $0.00079^{* *}$ \\
\hline Restrictions on Inflows $<0.5$ & 92 & 0.00137 & 0.00302 & $0.00004^{* * *}$ & $0.00045^{* * *}$ \\
\hline Restrictions on Outflows $>0.5$ & 41 & $0.02846^{* *}$ & 0.01084 & $0.00029^{* * *}$ & $0.00181 * * *$ \\
\hline Restrictions on Outflows $<0.5$ & 89 & 0.0038 & 0.00341 & $0.00003 * * *$ & $0.00038^{* * *}$ \\
\hline Overall Restrictions $>0.5$ & 39 & $0.03543^{* * *}$ & 0.01140 & -0.00000 & $0.00090 * *$ \\
\hline Overall Restrictions $<0.5$ & 91 & 0.00136 & 0.00305 & $0.00004 * * *$ & $0.00044^{* * *}$ \\
\hline \multicolumn{6}{|c|}{ Relating to the way FXI are conducted } \\
\hline \multicolumn{6}{|l|}{ By FX Mechanism } \\
\hline Auctions (Brazil) & 2 & 0.00185 & 0.00485 & -0.00022 & 0.00153 \\
\hline Auctions (Colombia) & 8 & $0.12072^{* *}$ & 0.04210 & $0.00864^{* * *}$ & $0.05214^{* * *}$ \\
\hline Auctions (Mexico) & 4 & 0.02305 & 0.02232 & -0.00000 & 0.02610 \\
\hline Auctions (Turkey) & 14 & $0.01136^{*}$ & 0.00611 & -0.00000 & -0.00010 \\
\hline Forwards & 2 & 0.00019 & 0.00119 & $0.00126^{* * *}$ & 0.00084 \\
\hline Spot & 108 & 0.00234 & 0.00277 & $0.00004^{* * *}$ & $0.00053^{* * *}$ \\
\hline \multicolumn{6}{|l|}{ By Announcement } \\
\hline Announced & 4 & $0.00503 *$ & 0.00193 & $0.00163^{* * *}$ & $0.00298^{* * *}$ \\
\hline Secret (Dirty) & 9 & 0.00987 & 0.00869 & -0.00006 & -0.00013 \\
\hline Others & 125 & $0.01092 * *$ & 0.00440 & $0.00003^{* * *}$ & $0.00042 * * *$ \\
\hline \multicolumn{6}{|l|}{ By Intended Central Bank Objective } \\
\hline Influence FX Level & 84 & $0.00387^{* *}$ & 0.00185 & $0.00003 * * *$ & $0.00042^{* * *}$ \\
\hline Influence Volatility & 35 & $0.02886^{*}$ & 0.01468 & 0.00000 & 0.00059 \\
\hline Influence Level \& Volatility & 6 & -0.00107 & 0.00134 & 0.00013 & 0.00019 \\
\hline Asymmetry (Sales over Total in $1^{s t}$ quartile) & 20 & -0.00549 & 0.00970 & $0.00042^{* * *}$ & 0.00025 \\
\hline Symmetry (Sales over Total in $2^{n d}$ or $3^{r d}$ quartile) & 30 & $0.01537 * *$ & 0.00743 & -0.00000 & $0.00060^{* *}$ \\
\hline Asymmetry (Sales over Total in $4^{t h}$ quartile) & 15 & 0.00886 & 0.00683 & 0.00001 & 0.00004 \\
\hline \multicolumn{6}{|l|}{ By Size of Intervention } \\
\hline Intervention Size in $1^{s t}$ quartile & 19 & 0.00304 & 0.00423 & $-0.00020^{* *}$ & $-0.00168^{* *}$ \\
\hline Intervention Size in $2^{\text {nd }}$ quartile & 15 & 0.00819 & 0.00752 & 0.00000 & $0.00042^{*}$ \\
\hline Intervention Size in $3^{r d}$ quartile & 15 & 0.00819 & 0.00752 & 0.00000 & $0.00042^{*}$ \\
\hline Intervention Size in $4^{t h}$ quartile & 17 & $0.03924 * *$ & 0.01628 & -0.00001 & -0.00020 \\
\hline
\end{tabular}

Authors' calculations. Sample means are computed by regressing effect sizes on each variable from the first column (SD is the standard deviation). FE and RE denote Fixed and Random Effects in the standard meta-analysis context. Trilemma measures are obtained from Aizenman et al. (2008), exchange rate regimes are obtained from Ilzetzki et al. (2019), and capital controls are obtained from Fernández et al. (2016). All other variables were obtained from Bloomberg, directly from each study, and from official central banks' websites (see Section 2.1). ***,**, and ${ }^{*}$ denote statistical significance at the 1,5 , and 10 percent level respectively. 
Table D8: Other Effects: FX Level in Response to a \$1 Billion Net USD Purchase (with daily frequency data)

\begin{tabular}{|c|c|c|c|c|c|}
\hline USD Purchases & Obs & Sample Mean & SD & $\mathrm{FE}$ & $\mathrm{RE}$ \\
\hline Total & 138 & $0.01068^{* * *}$ & 0.00402 & $0.00003^{* * *}$ & $0.00039^{* * *}$ \\
\hline \multicolumn{6}{|c|}{ Relating to Macroeconomic Variables } \\
\hline \multicolumn{6}{|l|}{ By GDP Classification } \\
\hline Low Income & 2 & -0.044 & 0.05600 & $0.01200 *$ & $0.01200^{*}$ \\
\hline Lower Middle Income & 13 & 0.00148 & 0.01756 & 0.00001 & 0.00024 \\
\hline Upper Middle Income & 62 & $0.02426 * * *$ & 0.00743 & -0.00000 & $0.00062 * *$ \\
\hline High Income & 61 & 0.00064 & 0.00225 & $0.00004 * * *$ & $0.00045^{* * *}$ \\
\hline \multicolumn{6}{|l|}{ By Financial Crisis } \\
\hline Systemic Banking Crisis $>10 \%$ of analyzed period & 13 & -0.0024 & 0.00306 & $0.00040^{* * *}$ & $0.00047 * * *$ \\
\hline Systemic Banking Crisis $<10 \%$ of analyzed period & 16 & 0.00287 & 0.00241 & $0.00003^{* * *}$ & $0.00059 * * *$ \\
\hline Systemic Banking Crisis Intensity $>$ mean & 29 & 0.00051 & 0.00194 & $0.00004 * * *$ & $0.00054^{* * *}$ \\
\hline Currency Crisis $>25 \%$ of analyzed period & 14 & -0.0117 & 0.01364 & -0.00000 & -0.00006 \\
\hline \multicolumn{6}{|l|}{ By Financial Deepening } \\
\hline Financial Deepening $>$ mean & 51 & 0.00229 & 0.00140 & $0.00004^{* * *}$ & $0.00048^{* * *}$ \\
\hline Financial Deepening $<$ mean & 76 & $0.01738^{* *}$ & 0.00702 & -0.00000 & $0.00041^{* *}$ \\
\hline \multicolumn{6}{|l|}{ By Exchange Rate Volatility } \\
\hline Exchange Volatility $>$ mean & 63 & 0.00347 & 0.00678 & $0.00002^{* * *}$ & $0.00030^{* * *}$ \\
\hline Exchange Volatility $<$ mean & 75 & $0.01675^{* * *}$ & 0.00467 & $0.00004 * * *$ & $0.00060^{* * *}$ \\
\hline \multicolumn{6}{|l|}{ By International Reserves } \\
\hline FX Reserves > mean & 50 & 0.0051 & 0.00315 & $0.00004 * * *$ & $0.00069^{* * *}$ \\
\hline FX Reserves < mean & 81 & $0.01584^{* *}$ & 0.00650 & $0.00002^{* *}$ & $0.00033^{* *}$ \\
\hline \multicolumn{6}{|l|}{ By Sovereign Debt (in foreign currency) } \\
\hline External Debt > mean & 27 & -0.00405 & 0.00858 & 0.00000 & -0.00001 \\
\hline External Debt $<$ mean & 38 & $0.03650 * * *$ & 0.01176 & -0.00000 & $0.00086 * *$ \\
\hline \multicolumn{6}{|l|}{ By Country's Credit Rating } \\
\hline Moodys > mean & 59 & 0.00265 & 0.00219 & $0.00004^{* * *}$ & $0.00050^{* * *}$ \\
\hline Moodys $<$ mean & 72 & $0.01918^{* *}$ & 0.00735 & -0.00000 & $0.00037^{* *}$ \\
\hline $\mathrm{S} \& \mathrm{P}>$ mean & 66 & $0.00394 *$ & 0.00221 & $0.00004 * * *$ & $0.00051 * * *$ \\
\hline $\mathrm{S} \& \mathrm{P}<$ mean & 65 & $0.01966^{* *}$ & 0.00809 & -0.00000 & $0.00033^{* *}$ \\
\hline Fitch $>$ mean & 66 & $0.00394 *$ & 0.00221 & $0.00004 * * *$ & $0.00051 * * *$ \\
\hline Fitch $<$ mean & 64 & $0.01978^{* *}$ & 0.00821 & 0.00000 & $0.00032^{* *}$ \\
\hline \multicolumn{6}{|c|}{ Relating to each Study } \\
\hline \multicolumn{6}{|l|}{ By Treatment Variable } \\
\hline Dummy & 21 & -0.00461 & 0.00947 & $0.00076^{* * *}$ & $0.00081^{* * *}$ \\
\hline No Dummy & 117 & $0.01343^{* * *}$ & 0.00440 & $0.00002^{* * *}$ & $0.00029^{* * *}$ \\
\hline \multicolumn{6}{|l|}{ By Publication Type } \\
\hline Web of Science - ISI & 67 & 0.00586 & 0.00406 & $0.00003^{* * *}$ & $0.00034^{* * *}$ \\
\hline Working Paper or Other & 60 & $0.01560 *$ & 0.00796 & $0.00002^{* * *}$ & $0.00062^{* * *}$ \\
\hline Impact Factor $>$ mean & 34 & 0.01068 & 0.00703 & $0.00002^{* * *}$ & $0.00033^{*}$ \\
\hline Impact Factor $<$ mean & 33 & 0.0009 & 0.00389 & $0.00052^{* * *}$ & $0.00033^{*}$ \\
\hline No. of Citations $>$ mean & 36 & 0.01724 & 0.01087 & -0.00000 & -0.00000 \\
\hline No. of Citations $<$ mean & 102 & $0.00837^{* *}$ & 0.00388 & $0.00004 * * *$ & $0.00053^{* * *}$ \\
\hline \multicolumn{6}{|l|}{ By Methodology } \\
\hline Event Study & 6 & $0.02098^{* *}$ & 0.00745 & 0.00077 & $0.00622^{*}$ \\
\hline GARCH & 89 & 0.00572 & 0.00515 & $0.00005 * * *$ & $0.00040 * * *$ \\
\hline IV \& 2 SLS & 9 & 0.01306 & 0.00720 & $0.00751^{* * *}$ & $0.00883^{* * *}$ \\
\hline OLS & 20 & 0.00929 & 0.00547 & $0.00002^{* * *}$ & $0.00069 * * *$ \\
\hline PSM & 5 & 0.00271 & 0.00158 & $0.00055^{* *}$ & 0.00071 \\
\hline RDD & 3 & $0.16296 * *$ & 0.03718 & $0.14774 * * *$ & $0.14774 * * *$ \\
\hline VAR VEC SUR & 2 & -0.00283 & 0.00317 & $0.00030^{* * *}$ & -0.00275 \\
\hline
\end{tabular}

Authors' calculations. Sample means are computed by regressing effect sizes on each variable from the first column (SD is the standard deviation). FE and RE denote Fixed and Random Effects in the standard meta-analysis context. Financial crises are obtained from Laeven and Valencia (2020). All other variables were obtained from Bloomberg, directly from each study, and from official central banks' websites (see Section 2.1). ${ }^{* *},{ }^{* *}$, and ${ }^{*}$ denote statistical significance at the 1,5 , and 10 percent level respectively. 


\section{Appendix E Alternative Classification of Exchange Rate Regimes}

Table E9: FX Level in Response to a $\$ 1$ Billion Net USD Purchase (by Exchange Rate Regime)

\begin{tabular}{|c|c|c|c|c|c|}
\hline USD Purchases & Obs & Sample Mean & $\mathrm{SD}$ & $\mathrm{FE}$ & $\mathrm{RE}$ \\
\hline \multicolumn{6}{|l|}{ Coarse Classification } \\
\hline Currency Board & 3 & -0.00273 & 0.00285 & -0.00013 & -0.00183 \\
\hline Pre-Announced Crawling Peg & 11 & $0.01407^{*}$ & 0.00724 & 0.00046 & $0.00695 * *$ \\
\hline Crawling Band & 55 & $0.02582^{* * *} *$ & 0.00890 & -0.00000 & $0.00091 * *$ \\
\hline Free Floating & 67 & -0.00125 & 0.00132 & $0.00004^{* * *}$ & $0.00040^{* * *}$ \\
\hline Freely Falling & 22 & 0.00086 & 0.00972 & 0.00008 & $0.00289^{* *}$ \\
\hline \multicolumn{6}{|l|}{ Fine Classification } \\
\hline De Facto Peg & 3 & -0.00273 & 0.00285 & -0.00013 & -0.00183 \\
\hline De Facto Crawling Peg & 7 & 0.02057 & 0.01084 & $0.01835^{* * *}$ & $0.01835^{* * *}$ \\
\hline De Facto Crawling Band narrower than or equal to $+/-2 \%$ & 4 & 0.00269 & 0.00128 & 0.00022 & 0.00147 \\
\hline Pre-Announced Crawling Band wider than or equal to $+/-2 \%$ & 2 & 0.036 & 0.01200 & $0.03157^{* * *}$ & $0.03305^{* * *}$ \\
\hline De Facto Crawling Band narrower than or equal to $+/-5 \%$ & 4 & -0.01125 & 0.03393 & 0.00038 & 0.02254 \\
\hline Moving Band narrower than or equal to $+/-2 \%$ & 3 & 0.00952 & 0.01285 & $-0.01237^{* * *}$ & 0.00356 \\
\hline De Facto Moving Band $+/-5 \% /$ Managed Floating & 46 & $0.02966^{* * * *}$ & 0.01014 & 0.00000 & $0.00091 * *$ \\
\hline Freely Floating & 67 & -0.00125 & 0.00132 & $0.00004^{* * *}$ & $0.00040^{* * *}$ \\
\hline Freely Falling & 22 & 0.00086 & 0.00972 & 0.00008 & $0.00289^{* *}$ \\
\hline
\end{tabular}

Authors' calculations. Sample means are computed by regressing effect sizes on each variable from the first column (SD is the standard deviation). FE and RE denote Fixed and Random Effects in the standard meta-analysis context. Coarse and Fine Classifications of exchange rate regimes are obtained from Ilzetzki et al. (2019). ***, **, and * denote statistical significance at the 1,5 , and 10 percent level respectively. 


\section{Appendix F Differences from other Meta-Analysis}

In this appendix we present differences with respect to Brychka et al. (2019). While our study collects a total of 74 empirical studies, Brychka et al. (2019) cover 12 studies. In total, there is an overlap of 11 studies. The remaining study is excluded from our sample due to our frequency criterion, i.e. we eliminate intra-daily studies such as the case of Dominguez (2006).

From the 11 studies that overlap:

- 3 studies coincide with our results.

- 2 studies differ since we use the latest version of publication. These include Broto (2013) and Frenkel et al. (2005).

- 6 studies differ on reported results:

- For net purchases in Dominguez (1993), we report a coefficient of -0.213 while Brychka et al. (2019) report a coefficient of -1.13 .

- For purchases in Aguilar and Nydahl (2000), we report a coefficient of -0.06 while Brychka et al. (2019) report a coefficient of -0.08 .

- For net purchases in Castrén (2004), we find a coefficient (FX volatility) of -0.0001 while Brychka et al. (2019) report a coefficient of -0.01 .

- For net purchases in Edison et al. (2006), we find a coefficient of -0.15 while Brychka et al. (2019) report a coefficient of 0.01 .

- For net purchases in Dominguez (1998), we find a coefficient (FX volatility) of 0.06 while Brychka et al. (2019) report a coefficient of 0.01 .

- For net purchases in Beine et al. (2002), we find a coefficient (FX volatility) of 0.001 while Brychka et al. (2019) report a coefficient of 0.03 . 